Provided for non-commercial research and education use. Not for reproduction, distribution or commercial use.

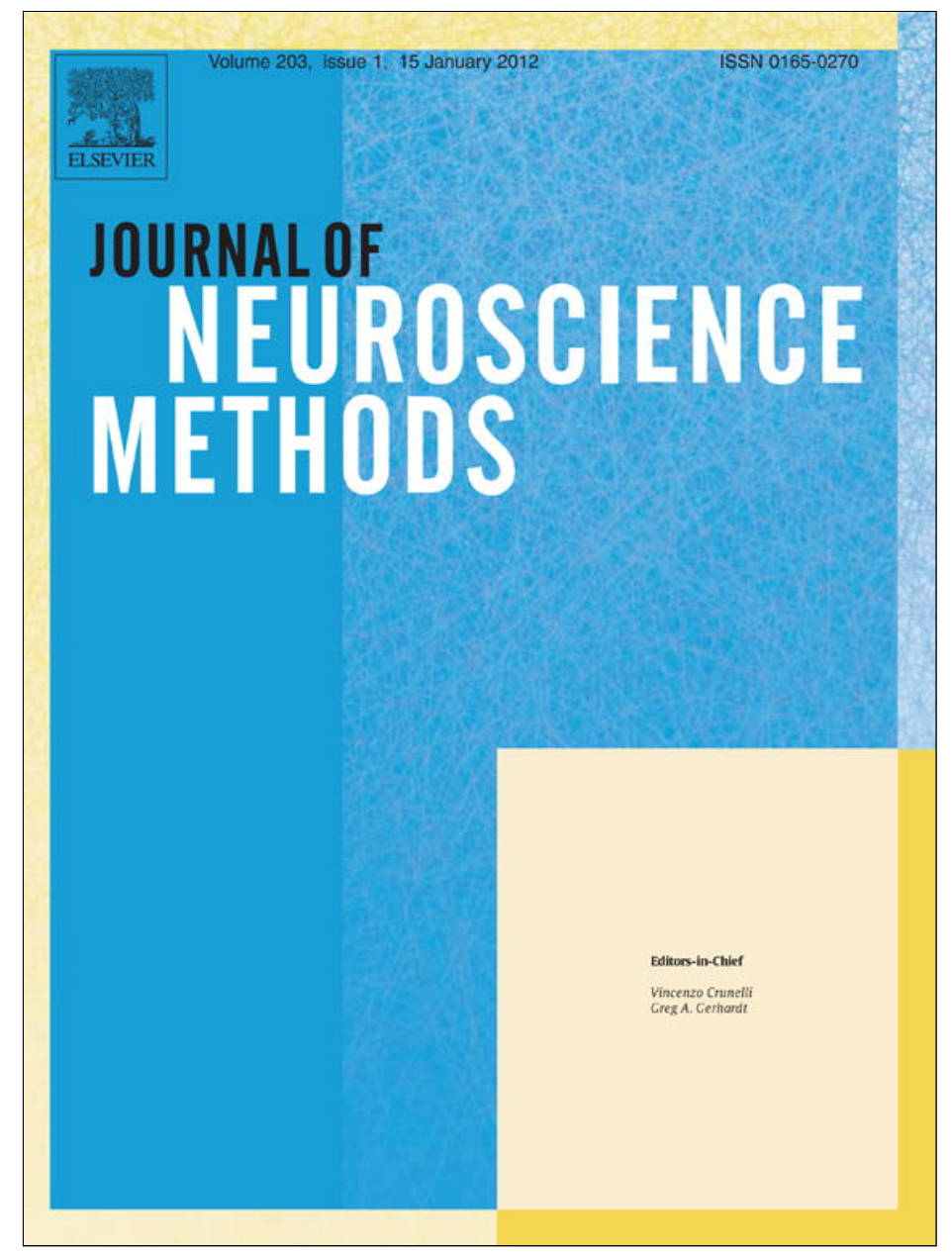

(This is a sample cover image for this issue. The actual cover is not yet available at this time.)

This article appeared in a journal published by Elsevier. The attached copy is furnished to the author for internal non-commercial research and education use, including for instruction at the authors institution and sharing with colleagues.

Other uses, including reproduction and distribution, or selling or licensing copies, or posting to personal, institutional or third party websites are prohibited.

In most cases authors are permitted to post their version of the article (e.g. in Word or Tex form) to their personal website or institutional repository. Authors requiring further information regarding Elsevier's archiving and manuscript policies are encouraged to visit:

http://www.elsevier.com/copyright 


\title{
An efficient method to limit microglia-dependent effects in astroglial cultures
}

\author{
Sophie Losciuto, Gauthier Dorban, Sébastien Gabel, Audrey Gustin, Claire Hoenen, Luc Grandbarbe, \\ Paul Heuschling, Tony Heurtaux* \\ Life Sciences Research Unit, Faculty of Science, Technology and Communication, University of Luxembourg, Campus Limpertsberg, \\ 162A, Avenue de la Faïencerie, L-1511, Luxembourg
}

\section{A R T I C L E I N F O}

\section{Article history:}

Received 3 January 2012

Received in revised form 19 March 2012

Accepted 21 March 2012

\section{Keywords:}

Brain

Astrocytes

Immune cells

Inflammation

Beta-amyloid

\begin{abstract}
A B S T R A C T
Microglia, the CNS resident macrophages, and astrocytes, the most abundant glial cell population, are both implicated in brain pathologies and can exhibit a pro-inflammatory phenotype. Microglial cells are known to rapidly and strongly react to brain insults. They will promote astrocyte activation and may lead to a vicious, self-perpetuating cycle of chronic inflammation. To obtain a better understanding of the individual role of both cell types, primary cells are frequently used in in vitro studies, but the purity of specific cell cultures remains rarely investigated. The aim of this study is to determine the effect of specific removal of microglial cells on the inflammatory properties of different glial cultures. Here, the removal of microglial contamination from mixed glial cultures to obtain astrocyte-enriched cultures was achieved using a magnetic cell sorting approach. Compared to mixed cultures, we clearly showed that these enriched cultures are only weakly activated by pro-inflammatory agents (lipopolysaccharide, interferon- $\gamma$ or beta-amyloid peptide). This finding was confirmed using twice-sorted astrocyte-enriched cultures and microglia-free cultures composed of neurosphere-derived astrocytes. Thus, we present evidence that the magnitude of the pro-inflammatory response is linked to the percentage of microglia in cultures. Due to their high reactivity to various insults or pro-inflammatory stimuli, microglia-derived effects could be credited to astrocytes in mixed glial cultures. Therefore, we highlight the importance of monitoring the presence of microglia in glial cultures since they can affect the interpretation of the results, especially when inflammatory processes are studied.
\end{abstract}

(c) 2012 Elsevier B.V. All rights reserved.

\section{Introduction}

In the central nervous system (CNS), glial cells have supportive roles for neurons but also act as the resident immune system cells, engaging several inflammatory processes to defend the brain from pathogens and helping it to recover from stress and injury (Farfara et al., 2008). However, in brain pathologies, chronic glial activation is a common event, which could promote a progressive dysfunction and loss of neurons in the CNS. Astrocytes and microglia are both glial cells whose physiological roles and responses upon activation are quite distinct. Astrocytes, the most abundant glial cell population, are essential for brain homeostasis and neuronal function. Although astrocytes play a significant role in maintaining normal CNS functions, after injury these glial cells may exert pathophysiological actions leading to neuronal damage (Sofroniew and Vinters, 2010). Microglial cells are the resident macrophages in the CNS (Beutner et al., 2010; Hanisch and Kettenmann, 2007; Dobrenis, 1998). These cells represent the first line of defense

\footnotetext{
* Corresponding author. Tel.: +352466644 6382; fax: +3524666446371.

E-mail address: tony.heurtaux@uni.lu (T. Heurtaux).
}

against pathogens or brain tissue injury. In their activated state, they have beneficial functions essential for neuron survival (Ekdahl et al., 2009). On the other hand, microglial overactivation can give rise to progressive neurotoxic consequences (Lull and Block, 2010; Block et al., 2007). Microglial activation can also promote astrocyte activation, which in turn can further activate microglia, thus possibly leading to a vicious cycle of overactivation that may contribute to a chronic inflammatory state, with continuously increasing production of pro-inflammatory mediators (Liu et al., 2011; Vallejo et al., 2010; Saijo et al., 2009; Henze et al., 2005; Zaheer et al., 2002).

In vitro experiments using near-pure glial cultures are nowadays widely used in order to avoid heterogeneous cell-cell interactions and to characterize cell-specific signaling pathways. Thus, diverse methods have been developed for cell separation and purification (for review, see Dainiak et al., 2007). Actually, the most widely used technique for harvesting a single glial population is dependent on a mechanical shake-off method (Floden and Combs, 2007), but this is wrought with issues as it often still leaves a mixture of different glial cells. Newer techniques are based on physical criteria like size, shape, and density. They include filtration and centrifugation approaches (Fuss et al., 2009; Lara and Chalmers, 2005; Graham, 
2001), and also affinity approaches based upon biochemical cell surface and biophysical characteristics (Cho et al., 2010). Other approaches are the use of anti-mitotic agents to inhibit microglial growth in primary astrocyte cultures (Hamby et al., 2006a; Solenov et al., 2004) or the differential adherence of various glial cells on cell culture plates (Jana et al., 2007). In this study, we used a more recent technique for primary microglia isolation (Marek et al., 2008). Based on an antigen-antibody-mediated magnetic cell sorting system using CD11b MicroBeads, this technique allowed to rapidly obtain pure astrocyte cultures after microglia depletion.

Our work further stresses the growing consensus that great care must be taken when using glial cultures to assess astrocyte responses to inflammatory stimuli, as even small levels of microglia will have a major influence on the observed effects. Therefore, without a rigorous quality check, microglia-derived effects could be attributed to astrocytes. Due to their high pro-inflammatory capacities, microglia rapidly detect and strongly respond to a large number of stimuli. The presence of microglia must not be underestimated and great caution should be taken when preparing primary glial cultures (Saura, 2007). Thus, we investigated whether classical pro-inflammatory stimuli, such as LPS, IFN $\gamma$ or beta-Amyloid $(A \beta)$ peptide, were able to activate different types of glial cell cultures: mixed glial cultures (called MGC1), astrocyte-enriched cultures (called AEC-M1 and AEC-M2), neurosphere-derived astrocyte cultures, and primary microglia cultures. We provide clear evidence that the magnitude of the pro-inflammatory response was dependent on the proportion of contaminating microglial cells in our cultures.

\section{Materials and methods}

\subsection{Mixed glial cultures}

Mixed glial cell cultures were prepared from newborn C57BL/6 mouse brains (Harlan, The Netherlands) (Fig. 1). Briefly, after carefully removing meninges and large blood vessels, the brains were pooled and then minced in cold phosphate-buffered saline (PBS) solution. The dissociation was completed by a 10 min incubation in $2 \mathrm{mM}$-cold EDTA. After washes and centrifugations, the cells were plated and grown in complete medium (Dulbecco's Modified Eagle Medium (DMEM) supplemented with $10 \%$ fetal bovine serum (FBS), $100 \mathrm{U} / \mathrm{ml}$ penicillin and $100 \mu \mathrm{g} / \mathrm{ml}$ streptomycin) at $37^{\circ} \mathrm{C}$ in a humidified atmosphere containing $5 \% \mathrm{CO}_{2}$. The culture medium was changed after 3 days of culture. After 8-10 days, mixed glial cultures (passage 0 or P0) had reached confluence, and microglia were detached by a $30 \mathrm{~min}$ shaking on a rotary shaker at $200 \mathrm{rpm}$ at $37^{\circ} \mathrm{C}$. Detached cells, mainly microglia (Iba1-positive cells $>95 \%$ ) were then plated in the same medium (astrocyte-conditioned medium) in a humidified atmosphere containing $5 \% \mathrm{CO}_{2}$ and were ready-touse $24 \mathrm{~h}$ later. Oligodendrocytes were subsequently detached from the mixed glial cultures (P0) by 2 days of washing and shaking steps on a rotary shaker at $200 \mathrm{rpm}$ at $37^{\circ} \mathrm{C}$ in a humidified atmosphere containing $5 \% \mathrm{CO}_{2}$. Afterwards, the culture medium was removed and mixed glial cultures were washed with PBS and incubated with $0.05 \%$ trypsin $/ 0.53 \mathrm{mM}$ EDTA at $37^{\circ} \mathrm{C}$ for $5 \mathrm{~min}$. Then, the trypsin was inactivated by the addition of complete medium and the cellular suspension was centrifuged at $300 \times \mathrm{g}$ at $4{ }^{\circ} \mathrm{C}$ for $10 \mathrm{~min}$. The cell pellet was resuspended in complete medium and then plated. After 6-7 days, mixed glial cultures (P1), called MGC1, had reached confluence. To detach residual microglia and oligodendrocytes, these cultures were shaken again for 2 days with 3 washings per day on a rotary shaker at $200 \mathrm{rpm}$ at $37^{\circ} \mathrm{C}$ in a humidified atmosphere containing $5 \% \mathrm{CO}_{2}$. Finally, fresh complete medium was added and these MGC1 were ready-to-use. Cell culture products were purchased from Invitrogen (Scotland).

\subsection{Magnetic cell sorting for astrocyte-enriched cultures}

As indicated in Fig. 1, mixed glial cultures (P1) or MGC1, obtained after the trypsinization step (described above), were further worked-up by magnetic cell sorting (MACS). After trypsinization and centrifugation at $300 \times \mathrm{g}$ at $4{ }^{\circ} \mathrm{C}$ for $10 \mathrm{~min}$, the cell pellet was resuspended in a separation buffer containing PBS, pH 7.2, $0.5 \%$ bovine serum albumin (BSA) and $2 \mathrm{mM}$ EDTA. The cell suspension was centrifuged at $300 \times g$ at $4{ }^{\circ} \mathrm{C}$ for $10 \mathrm{~min}$. Following manufacturer's instruction, $1 \times 10^{7}$ cells were resuspended in $90 \mu \mathrm{l}$ of buffer and $10 \mu \mathrm{l}$ of CD11b MicroBeads (MicroBeads conjugated to monoclonal rat anti-mouse $\mathrm{CD} 11 \mathrm{~b}$ antibody, Miltenyi Biotec, The Netherlands). The suspension was incubated at $4{ }^{\circ} \mathrm{C}$ for $20 \mathrm{~min}$ with gentle mixing after $10 \mathrm{~min}$. During the incubation step, the CD11bpositive cells, microglia, were magnetically labeled with CD11b MicroBeads. Then, cells were washed with the separation buffer and centrifuged at $300 \times \mathrm{g}$ at $4^{\circ} \mathrm{C}$ for $10 \mathrm{~min}$. The cellular pellet was resuspended in $500 \mu \mathrm{l}$ of separation buffer for $1 \times 10^{8}$ cells. A LS column (Miltenyi Biotec) was fixed into the MidiMACS magnetic separation unit (Miltenyi Biotec) and washed with $3 \mathrm{ml}$ of separation buffer. The cell suspension was applied on the column and three washings of $3 \mathrm{ml}$ of separation buffer were performed with the same collecting tube. The unlabeled-cell fraction, mainly astrocytes, was passed through the column. The LS column was then detached from the magnetic separator and flushed with $5 \mathrm{ml}$ of separation buffer. This step was performed to collect CD11bpositive cells. Both cellular fractions were centrifuged at $300 \times \mathrm{g}$ at $4^{\circ} \mathrm{C}$ for $10 \mathrm{~min}$. The astrocyte-enriched fraction (called AEC-M1), corresponding to the $\mathrm{CD} 11 \mathrm{~b}$-negative fraction, was resuspended in complete medium before plating. After 6-7 days, AEC-M1 were confluent and ready-to-use. The CD11b-positive fraction, microglia, were plated in astrocyte-conditioned medium and were ready-touse $24 \mathrm{~h}$ later.

In order to vastly reduce microglial contamination, a second magnetic cell sorting (as previously described) was practiced from AEC-M1 to obtain even purer astrocyte cultures (AEC-M2). After 6-7 days, AEC-M2 were confluent and ready-to-use.

\subsection{Neurosphere-derived astrocyte cultures}

Primary cultures of neurospheres were obtained from embryonic murine neural stem cells derived from the subventricular zone (SVZ) of embryonic day 14 (E14) C57BL/6 mouse embryos as described previously (Grandbarbe et al., 2003). The SVZ of embryonic brain was extracted, triturated mechanically with a fired-narrowed Pasteur pipette. Dissociated cells were centrifuged at $300 \times g$ for $5 \mathrm{~min}$, washed once and then plated in noncoated 6 -well plates until neurospheres appeared. Neurospheres were cultured in Neurobasal-A medium supplemented with $1 \%$ B27 without vitamin A, $2 \mathrm{mM}$ L-glutamine, $100 \mathrm{U} / \mathrm{ml}$ penicillin, $100 \mu \mathrm{g} / \mathrm{ml}$ streptomycin and $20 \mathrm{ng} / \mathrm{ml}$ recombinant mouse Epidermal Growth Factor (rmEGF). These neurospheres were passaged by chemical, non-enzymatic dissociation every 5-6 days and reseeded as single cells at a density of $1 \times 10^{6}$ cells $/ \mathrm{ml}$. Neurospheres were differentiated into astrocytes by plating them on poly-L-ornithine coated flasks in DMEM containing 10\% FBS and 1\% antibiotics (Crocker et al., 2008). The culture medium was renewed after 3 days of differentiation and subsequently once a week. After 6 weeks of differentiation, the cells were considered to be completely differentiated into mature astrocytes.

\subsection{Cell treatments}

All treatments were applied on confluent cultures. Lipopolysaccharide (LPS 055:B5 from Escherichia coli, Sigma, Belgium) was added at $1 \mu \mathrm{g} / \mathrm{ml}$ on mixed and enriched glial cultures but at 


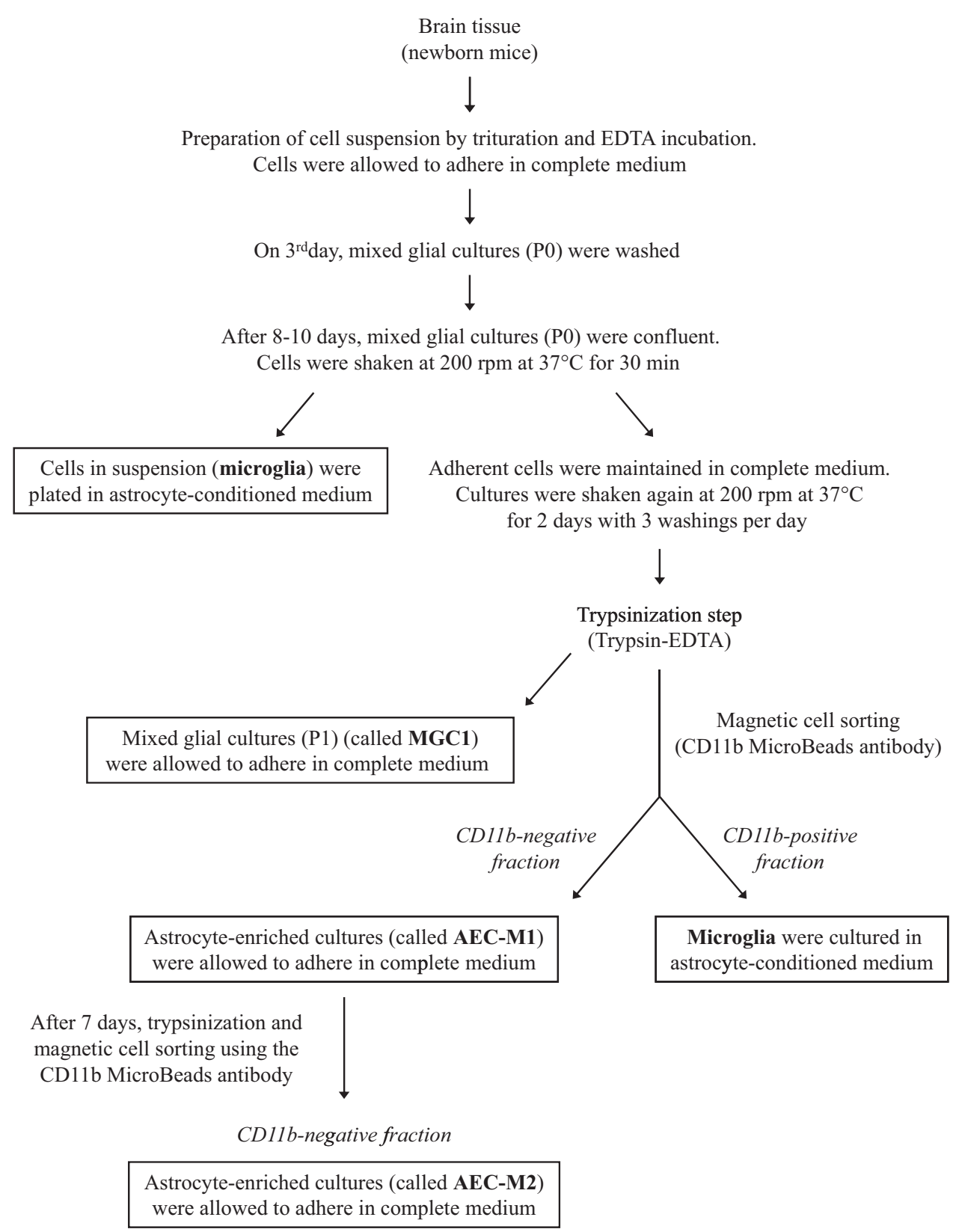

Fig. 1. Schematic drawing representing the cell isolation process.

only $1 \mathrm{ng} / \mathrm{ml}$ on primary microglia, since a higher concentration is deleterious for these cells. IFN $\gamma$ (Hycult Biotechnology, The Netherlands) was used at $50 \mathrm{U} / \mathrm{ml}$. The $A \beta(1-42)$ peptide (Bachem, Germany) was initially dissolved to $5 \mathrm{mM}$ in DMSO, separated into aliquots in sterile tubes and stored at $-20^{\circ} \mathrm{C}$. The stock aliquot was diluted to $0.5 \mathrm{mM}$ in DMEM containing $1 \%$ antibiotics $(100 \mathrm{U} / \mathrm{ml}$ penicillin and $100 \mu \mathrm{g} / \mathrm{ml}$ streptomycin). This $A \beta$ preparation was added directly to cultures at a final concentration of $5 \mu \mathrm{M}$.

\subsection{Cellular viability assay}

Mitochondrial function was assessed as an index of cellular viability using the MTT method. This assay measures the ability of mitochondrial dehydrogenases to convert 3-[4,5-dimethylthiazol2-yl]-2,5-diphenyltetrazolium bromide (MTT) to colored insoluble formazan. Cells were seeded on 48-well plate at an initial density of $2 \times 10^{5}$ cells/well. After treatment, cells were incubated for $3 \mathrm{~h}$ at $37^{\circ} \mathrm{C}$ with MTT $(0.35 \mathrm{mg} / \mathrm{ml})$ diluted in PBS. Then, the medium was removed, and cells were lysed by addition of $100 \%$ DMSO. Absorbance was measured at $540 \mathrm{~nm}$ using a microplate reader (TECAN, Austria). Viability was estimated from the absorbance of treated versus untreated cells.

\subsection{Flow cytometry}

The MACS-based sorting of microglial cells from mixed glial cultures was assessed by flow cytometry. Cells were harvested by trypsinization, centrifuged and resuspended in 3\% BSA in PBS. For intracellular markers, cells were previously fixed and permeabilized in PBS-paraformaldehyde $4 \%$ and $0.01 \%$ of Triton X100 at $4{ }^{\circ} \mathrm{C}$ for $30 \mathrm{~min}$. After a washing step, cells were incubated for $45 \mathrm{~min}$ with primary antibodies: rabbit anti-Iba1 (1:100, Biocare Medical, USA) or Cy3-labeled mouse anti-GFAP (1:800, Sigma, Belgium). Then, cells were stained with Cy2-conjugated anti-rabbit (1:1000, Jackson ImmunoResearch, England). The cells were washed in PBS after each incubation step. As negative controls, the same staining 
procedure was repeated in parallel with the corresponding isotype control antibodies (Jackson ImmunoResearch). The samples were analyzed on a flow cytometer (FACS Canto, Becton Dickinson) and data analysis was performed using WinMDI software (Scripps Research Institute, USA).

\subsection{Immunofluorescence}

Cells were cultured on poly-L-ornithine coated coverslips for one week and then fixed with paraformaldehyde (4\% in PBS) for $20 \mathrm{~min}$ at room temperature, and permeabilized for $5 \mathrm{~min}$ in PBS containing $0.3 \%$ Triton X100. Following 3 washings in PBS, the blocking step was realized with $3 \%$ BSA in PBS at room temperature for $30 \mathrm{~min}$. The cells were then incubated overnight at $4{ }^{\circ} \mathrm{C}$ with Cy3-labeled mouse anti-GFAP (1:800, Sigma) and rabbit antiIba1 (1:300, Biocare Medical). After washing steps with PBS, cells were incubated with Cy2-conjugated anti-rabbit (1:1000, Jackson ImmunoResearch) at room temperature for one hour. The cells were washed 3 times with PBS, and stained with DAPI (1:5000) for $5 \mathrm{~min}$. Cells were then washed, mounted with Fluoromount G (SouthernBiotech, USA), and observed under a LSM 510 META inverted confocal microscope (Carl Zeiss Micro Imaging, Göttingen, Germany) at a 40 -fold magnification.

\subsection{Real-time reverse transcription-polymerase chain reaction (RT-PCR) analysis}

Total RNA was isolated from glial cultures using the Invisorb ${ }^{\mathrm{TM}}$ Spin Cell RNA Mini Kit (Invitek, Germany) according to the manufacturer's protocol. Total RNA was recovered in elution buffer and quantified from the absorbance at $260 \mathrm{~nm}$. The purity was verified by spectrophotometry (absorbance ratio at $260 \mathrm{~nm}$ versus $280 \mathrm{~nm}$ ). The RNA electrophoresis Experion system (Bio-Rad, CA) was used to confirm the absence of RNA degradation and genomic contamination. Complementary DNA (cDNA) was synthesized from RNA samples using $0.5 \mu \mathrm{g}$ of total RNA and the ImProm-II Reverse Transcription System with $0.5 \mu \mathrm{g} /$ reaction oligo(dT) as primer. The RNA and oligo(dT) were denaturated at $70^{\circ} \mathrm{C}$ for $5 \mathrm{~min}$ and immediately chilled on ice for at least $5 \mathrm{~min}$. The reverse transcription reaction was performed in a total volume of $40 \mu$ by mixing $2 \mu \mathrm{l}$ ImProm-II ${ }^{\mathrm{TM}}$ reverse transcriptase, $25 \mathrm{mM} \mathrm{MgCl}_{2}$, $0.5 \mathrm{mM}$ of each dNTP, and $1 \mu \mathrm{l}$ of Recombinant RNasin ${ }^{\circledR}$ Ribonuclease inhibitor in ImProm-II 5X Reaction Buffer. Samples were incubated for $1 \mathrm{~h}$ at $42{ }^{\circ} \mathrm{C}$ and $15 \mathrm{~min}$ at $70^{\circ} \mathrm{C}$ to inactivate the reverse transcriptase. A $1 \mu \mathrm{l}$ aliquot of cDNA was used for each amplification by real-time PCR and added to the incubation mixture containing $8 \mu \mathrm{l}$ of $2 \mathrm{X} \mathrm{iQ}^{\mathrm{TM}}$ SYBR Green Supermix, $0.8 \mu \mathrm{l}$ of each $12.5 \mu \mathrm{M}$ optimized forward and reverse primers in a final volume of $20 \mu \mathrm{l}$. Primer sequences (Table 1) were designed using the Beacon Designer Software (Bio-Rad). PCR analysis were performed on a Bio-Rad iCycler (iQ5 Real-Time PCR Detection System) using a 2-stage program provided by the manufacturer: $3 \mathrm{~min}$ at $95^{\circ} \mathrm{C}$ followed by 40 cycles, consisting of denaturation at $95^{\circ} \mathrm{C}$ for $10 \mathrm{~s}$ and annealing/extension at a temperature between $52.5^{\circ} \mathrm{C}$ and $60.5^{\circ} \mathrm{C}$ for $30 \mathrm{~s}$. The change of reporter fluorescence from each reaction tube was monitored. Analysis of gene expression was performed using the comparative threshold cycle $\left(C_{t}\right)$ method. The threshold cycle of each gene was determined as PCR cycles at which an increase in reporter fluorescence above a baseline signal was observed (Table 2). The target gene was normalized to the endogenous reference gene, Rpl27 (a housekeeping gene coding for a ribosomal protein). The mRNA expression fold change was calculated using the expression $2^{-\mathrm{ddCt}}$, where $\mathrm{ddCt}=\left(C_{\mathrm{t}} \text {,target }-C_{\mathrm{t}} \text {, Rpl27 }\right)_{\text {treated sample }}$ $-\left(C_{\mathrm{t}, \text { target }}-C_{\mathrm{t}, \mathrm{Rp} 127}\right)_{\text {control sample }}$.
Table 1

Sequences of the different real-time PCR primers.

\begin{tabular}{|c|c|c|}
\hline $\begin{array}{l}\text { Target gene } \\
\text { (accession number) }\end{array}$ & Sequence $\left(5^{\prime}-3^{\prime}\right)$ & Product size \\
\hline Nos2 (NM_010927) & $\begin{array}{l}\text { f: AGCCCTCACCTACTTCCTG } \\
\text { r: САATCTCTGCCTATCCGTCTC }\end{array}$ & $100 \mathrm{bp}$ \\
\hline Ptgs2 (NM_011198) & $\begin{array}{l}\text { f: GCCTGGTCTGATGATGTATGC } \\
\text { r: GAGTATGAGTCTGCTGGTTTGG }\end{array}$ & $124 \mathrm{bp}$ \\
\hline Tnf (NM_013693) & $\begin{array}{l}\text { f: GGTTCTGTCCCTTTCACTCAC } \\
\text { r: TGCCTCTTCTGCCAGTTCC }\end{array}$ & $107 \mathrm{bp}$ \\
\hline Il1 $\beta$ (NM_008361) & $\begin{array}{l}\text { f: GCTTCAGGCAGGCAGTATC } \\
\text { r: AGGATGGGCTCTTCTTCAAAG }\end{array}$ & $133 \mathrm{bp}$ \\
\hline Il6 (NM_031168) & $\begin{array}{l}\text { f: ACCGCTATGAAGTTCCTCTC } \\
\text { r: CTCTGTGAAGTCTCCTCTCC }\end{array}$ & $117 \mathrm{bp}$ \\
\hline Ccl2 (NM_011333) & $\begin{array}{l}\text { f: АCTCACCTGCTGCTACTCATTC } \\
\text { r: GCTTCTTTGGGACACCTGCTG }\end{array}$ & $97 \mathrm{bp}$ \\
\hline Ccl3 (NM_011337) & $\begin{array}{l}\text { f: TTTGAAACCAGCAGCCTTTG } \\
\text { r: CAGGTCAGTGATGTATTCTTGG }\end{array}$ & $114 \mathrm{bp}$ \\
\hline Gfap (NM_010277) & $\begin{array}{l}\text { f: GGTTGAATCGCTGGAGGAG } \\
\text { r: CTGTGAGGTCTGGCTTGG }\end{array}$ & $131 \mathrm{bp}$ \\
\hline Itgam (NM_008401) & $\begin{array}{l}\text { f: TGGACGCTGATGGCAATACC } \\
\text { r: GGCAAGGGACACACTGACAC }\end{array}$ & $94 \mathrm{bp}$ \\
\hline Aif1 (NM_019467) & $\begin{array}{l}\text { f: TTCCCAAGACCCACCTAG } \\
\text { r: TCCTCATACATCAGAATCATTC }\end{array}$ & 142 bp \\
\hline Rpl27 (NM_011289) & $\begin{array}{l}\text { f: ACATTGACGATGGCACCTC } \\
\text { r: GCTTGGCGATCTTCTTCTTG }\end{array}$ & $111 \mathrm{bp}$ \\
\hline
\end{tabular}

All reagents for reverse transcription and real-time PCR were obtained from Promega (CA) and Bio-Rad, respectively.

\subsection{Measurement of pro-inflammatory mediator release}

Cells were seeded on 6-well plates at an initial density of $10^{5}$ cells/well. After 6-7 days, cultures were confluent and readyto-use. The release of nitrite, a stable metabolite of nitric oxide (NO), was measured after 24 and $48 \mathrm{~h}$ of LPS, IFN $\gamma$ and $A \beta$ exposure. The concentration of nitrite was determined in culture supernatants by the Griess assay. The production of prostaglandins $E_{2}$ $\left(\mathrm{PGE}_{2}\right)$ and TNF $\alpha$ was measured after $24 \mathrm{~h}$ of LPS, IFN $\gamma$ and $A \beta$ exposure. $\mathrm{PGE}_{2}$ and TNF $\alpha$ release were measured in the medium of the different cultures with a commercially available Enzyme ImmunoAssay kit (Assay Designs, USA), and a sandwich Enzyme Linked ImmunoSorbent Assay (R\&D Systems, USA), respectively. The protein content was determined using the Dye Reagent (BioRad) by measuring the absorbance at $595 \mathrm{~nm}$, using bovine serum albumin standards.

\subsection{Statistical analysis}

For comparison of means between two different treatments, statistical analysis was done by Student's $t$-test (two-sample assuming equal variances). For comparison of multiple treatments, results were analyzed by an ANOVA followed by a Fisher's exact test. Differences between groups were considered as significant when $p$-values were less than 0.05 . Results are expressed as mean \pm SEM from at least three independent experiments.

\section{Results}

Following the experimental procedure described in Fig. 1, we have prepared mixed glial cultures (P0) from the brains of newborn mice. From these cultures, we were able to prepare other glial cultures, such as mixed glial cultures (MGC1), but also astrocyte-enriched cultures (AEC-M1), twice-sorted astrocyteenriched cultures (AEC-M2) and microglial cultures. In this study, we have also generated microglia-free cultures composed of neurosphere-derived astrocytes. 
Table 2

Threshold cycle $\left(C_{\mathrm{t}}\right)$ value of the target genes in the different cultures.

\begin{tabular}{llll}
\hline Target gene (accession number) & MGC1 & AEC-M1 & Neurosphere-derived astrocytes \\
\hline Nos2 (NM_010927) & 36.0 & 36.0 & 36.0 \\
Ptgs2 (NM_011198) & 28.0 & 27.5 & 33.5 \\
Tnf (NM_013693) & 29.0 & 36.0 & 34.5 \\
Il1ß (NM_008361) & 30.5 & 35.5 & 36.5 \\
Il6 (NM_031168) & 31.5 & 31.5 & 37.0 \\
Ccl2 (NM_011333) & 25.0 & 26.5 & 28.0 \\
Ccl3 (NM_011337) & 27.0 & 35.0 & 31.5 \\
Gfap (NM_010277) & 21.0 & 21.0 & 20.5 \\
Itgam (NM_008401) & 29.2 & 34.4 & 36.0 \\
Aif1 (NM_019467) & 24.6 & 30.8 & 38.2 \\
Rpl27 (NM_011289) & 20.0 & 20.5 & 20.5 \\
\hline
\end{tabular}

\subsection{Analysis of the different glial cell culture preparations}

Immunocytochemistry analysis revealed that the number of microglial cells (Iba1-positive cells) in MGC1 was much higher compared to the ones contained in AEC-M1 (Fig. 2). Mouse astrocytes obtained by this separation process showed typical astrocyte morphology as well as astrocytic marker expression (GFAP), which was slightly lower than in MGC1. In both cultures, some cells were negative for both Iba1 and GFAP markers. Furthermore, quantitative data have been obtained by FACS analysis (Fig. 3). As shown in Fig. 3A, a MACS separation increased the GFAP-positive cells from about $60 \%$ in MGC1 to 70\% in AEC-M1. The percentage of microglial cells (Iba1-positive cells) has also been determined in both cultures. Before cell sorting separation, Iba1-positive cells represented $9-10 \%$ of the culture (Fig. 3B), whereas Iba1-positive cell number decreased to $1-1.5 \%$ of the total cells in enriched cultures (Fig. $3 \mathrm{C}$ ).

Cell sorting by CD11b MicroBeads was used to obtain astrocyteenriched cultures, but also microglial cultures (>95\% Iba1-positive cells, data not shown).
3.2. Effects of pro-inflammatory stimuli: assessment of $m R N A$ levels

In order to evaluate the consequences of the presence of microglial cells in our astrocyte cultures, pro-inflammatory conditions were induced by treating MGC1 and AEC-M1 with LPS, IFN $\gamma$ and $A \beta$. Pro-inflammatory gene expressions were assessed by realtime PCR (Fig. 4).

In MGC1, a $6 \mathrm{~h}$ LPS exposure strongly induced the expression of Nos2 (Fig. 4A), Ptgs2 (Fig. 4B), Tnf (Fig. 4C), Il1 $\beta$ (Fig. 4D) and Il6 (Fig. 4E) as well as $\mathrm{Ccl} 2$ and $\mathrm{Ccl} 3$ chemokines (data not shown). In AEC-M1, where the percentage of microglial cells was about 10fold lower than in MGC1, the expression of these pro-inflammatory genes was much lower compared to mixed culture responses: Nos2 (-90\%), Ptgs2 (-85\%), Tnf (-95\%), Il1ß (-97\%), Il6 (-95\%), Ccl2 ( $-50 \%$, data not shown) and $\mathrm{Ccl} 3$ ( $-90 \%$, data not shown).

IFN $\gamma$ and $A \beta$ were less potent than LPS in both glial cultures, but their effects were still different between MGC1 and AEC-M1 cultures. In MGC1, IFN $\gamma$ and $A \beta$ induced Nos2 expression (Fig. 4F)

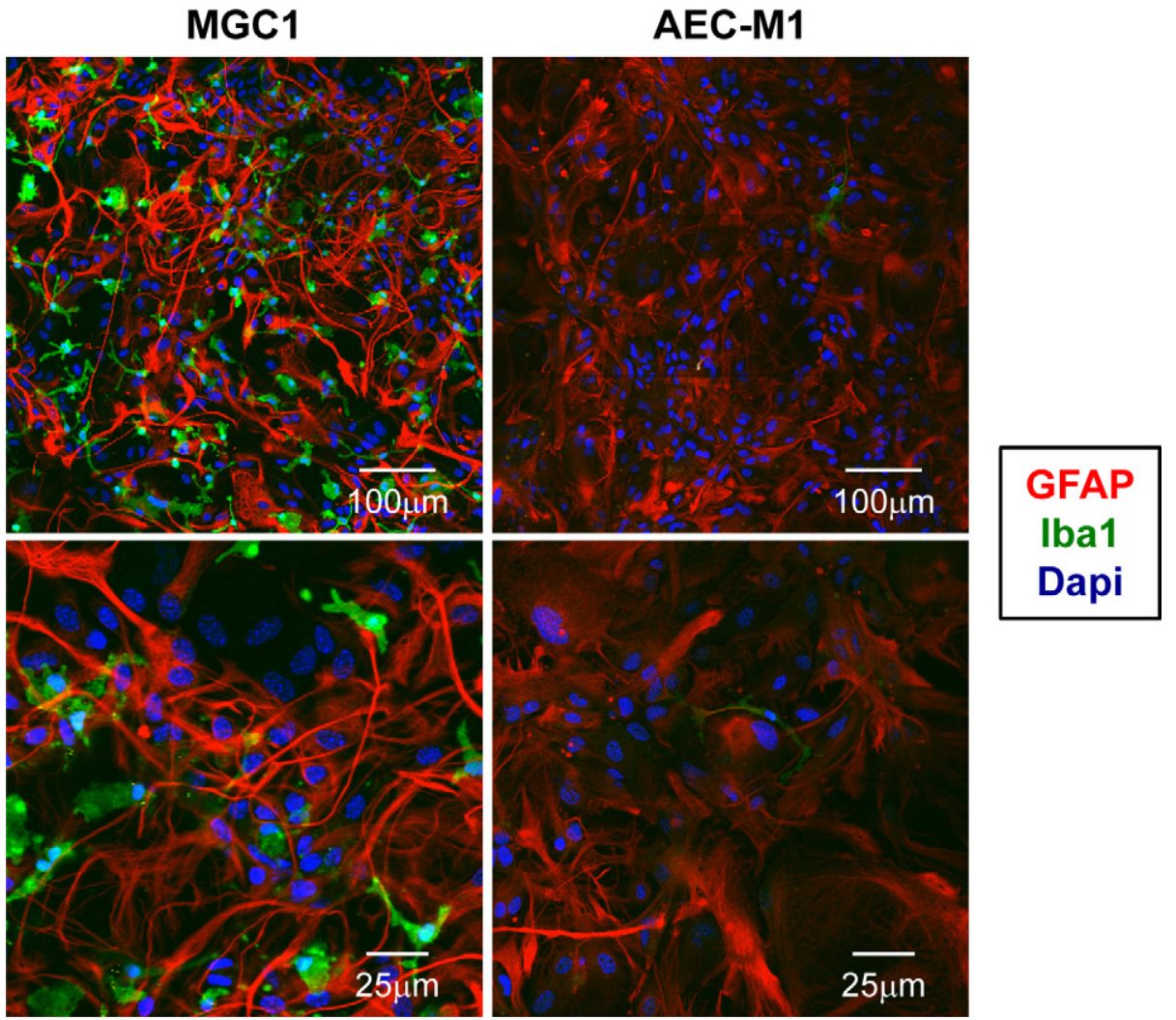

Fig. 2. Astrocyte and microglial cells in cultures. MGC1 and AEC-M1 were labeled with anti-GFAP antibody (red) in combination with the microglial marker Iba1 (green) and counterstained with nuclear stain DAPI (blue). (For interpretation of the references to color in this figure legend, the reader is referred to the web version of this article.) 

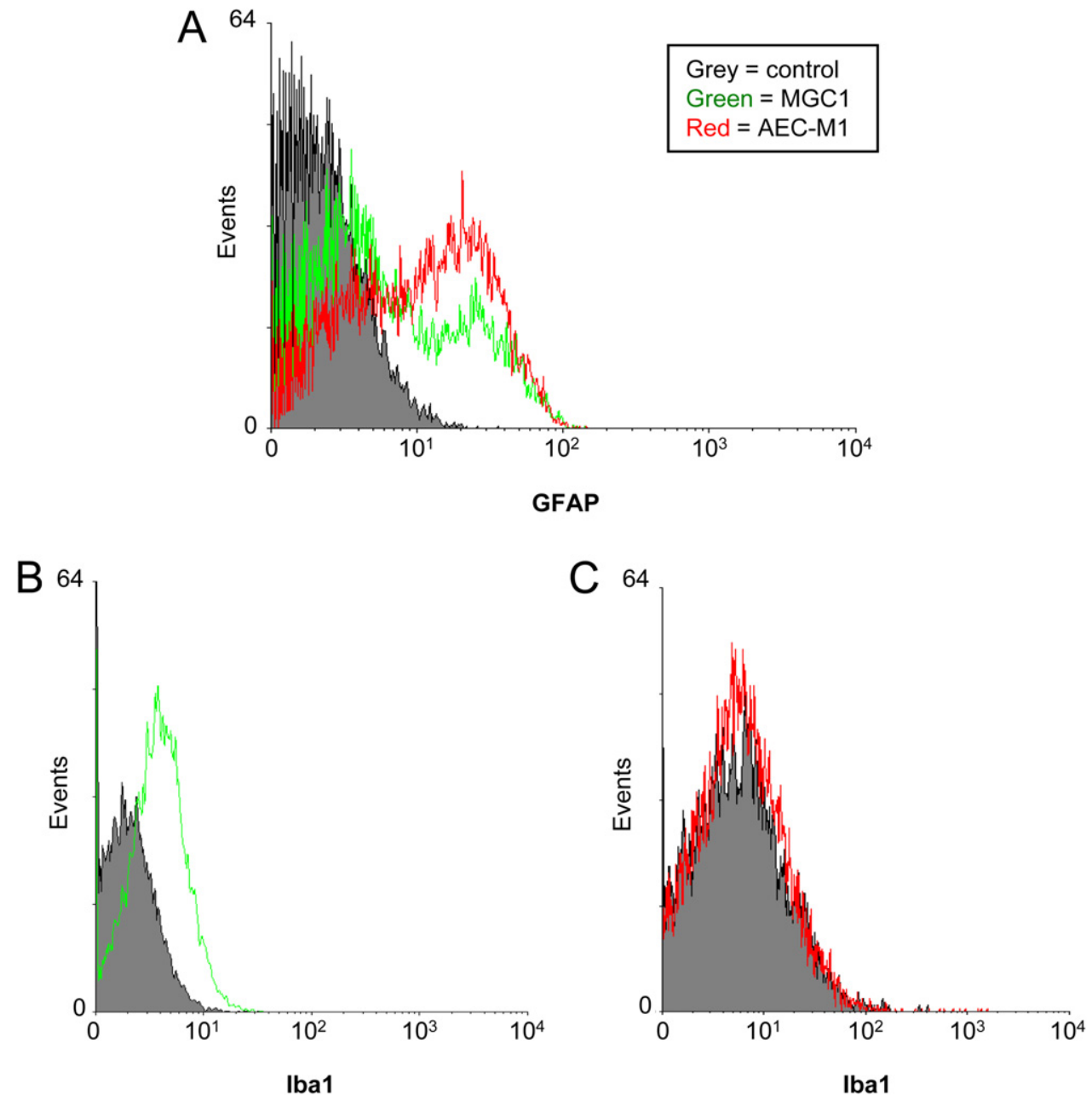

Fig. 3. Quantitative assessment of astrocyte and microglia populations by flow cytometry. The different glial cell populations were immunostained for flow cytometry analysis. GFAP (A) and Iba1-positive cells (B and C) were determined in both MGC1 (green events) and AEC-M1 (red events). For negative control (grey events), the same staining procedure was repeated with the secondary antibodies alone. Data analysis was performed using WinMDI software (Scripps Research Institute, USA). This is a representation of one out of three experiments. All experiments showed similar profiles. (For interpretation of the references to color in this figure legend, the reader is referred to the web version of this article.)

by respectively 25 -fold and 5 -fold compared to the control level. On the contrary, after magnetic separation, an IFN $\gamma$ exposure induced lower Nos2 expression (4.5-fold), whereas $A \beta$ had no effect on it. In both conditions, Ptgs2 up-regulation (Fig. 4G) was similar. Control expression levels of Tnf and Il1 $\beta$ (respectively Fig. $4 \mathrm{H}$ and I) were higher in MGC1 due to increased basal expression levels in microglia compared to astrocytes (Table 2). Thus, in MGC1, IFN $\gamma$ and $A \beta$ up-regulated Tnf by respectively 4.4-fold and 2-fold (Fig. $4 \mathrm{H}$ ). $A \beta$ also increased Il1 $\beta$ expression (4-fold) contrary to IFN $\gamma$, which decreased Il1 $\beta$ expression (-20\%). In AEC-M1, these two pro-inflammatory compounds had different effects on the expression of Tnf and Il1 $\beta$. An IFN $\gamma$ exposure up-regulated Tnf expression by 1.6 -fold whereas $A \beta$ had no effect. However, an $A \beta$ exposure up-regulated Il1 $\beta$ expression (2-fold induction) whereas IFN $\gamma$ had no effect. IFN $\gamma$ and $A \beta$ also induced a higher Il6 overexpression in MGC1 compared to AEC-M1 (Fig. 4J).

\subsection{Comparison with neurosphere-derived astrocyte cultures}

Neurosphere-derived astrocytes are considered as pure astrocytes. In response to an inflammatory stimulus (Fig. 5), neurosphere-derived astrocytes reacted to TNF $\alpha$ (data not shown) and IFN $\gamma$ exposure. The presence of IFN $\gamma$ increased gene expression levels of Nos2, Ptgs2, Tnf and Il6 (respectively Fig. 5A-D) but, in contrast to AEC-M1 cultures, LPS exposure did not increase Nos2, Tnf, and Il6 expression. Moreover, a LPS treatment induced a little increase of COX2 expression (2.2-fold). After IFN $\gamma$ and $A \beta$ treatments, the activation profile observed in neurosphere-derived astrocytes was the same than the one found in AEC-M1. However, Il1 $\beta$ expression was not detectable in neurosphere-derived astrocytes. In these conditions, the Gfap expression level was not modulated by pro-inflammatory activations (Fig. 5E).

\subsection{Comparison with primary microglia cultures}

Compared with MGC1 and AEC-M1, primary mouse microglia were highly sensitive to LPS $(1 \mathrm{ng} / \mathrm{ml}), \operatorname{IFN} \gamma(50 \mathrm{U} / \mathrm{ml})$ and $A \beta$ $(5 \mu \mathrm{M})$ exposures (Table 3 ). As expected, primary microglia showed

Table 3

Pro-inflammatory phenotype in primary microglia.

\begin{tabular}{lccr}
\hline Target genes & \multicolumn{1}{l}{ LPS } & \multicolumn{1}{l}{ IFN $\gamma$} & \multicolumn{1}{c}{ A $\beta$} \\
\hline Nos2 & $22,737.9 \pm 1932.8$ & $41.9 \pm 5.8$ & $11.2 \pm 2.2$ \\
Ptgs2 & $3008.3 \pm 240.0$ & $37.3 \pm 3.6$ & $28.5 \pm 3.8$ \\
Tnf & $1986.1 \pm 253.6$ & $5.7 \pm 1.6$ & $15.1 \pm 2.1$ \\
Il1 $\beta$ & $3482.8 \pm 214.2$ & $0.2 \pm 0.04$ & $20.7 \pm 1.1$ \\
Ccl2 & $636.7 \pm 54.2$ & $12.3 \pm 0.3$ & $3.3 \pm 0.5$ \\
Ccl3 & $101.4 \pm 11.3$ & $0.2 \pm 0.03$ & $7.5 \pm 0.8$ \\
\hline
\end{tabular}




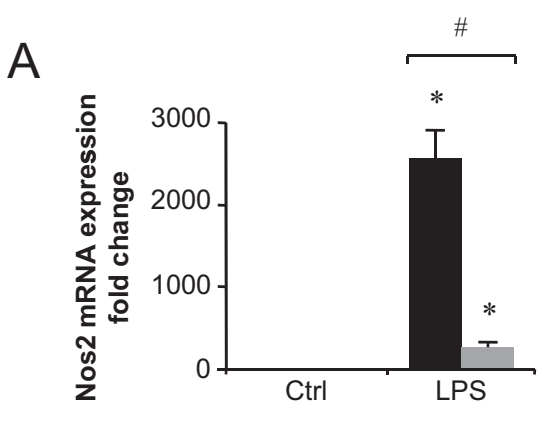

$\mathrm{B}$

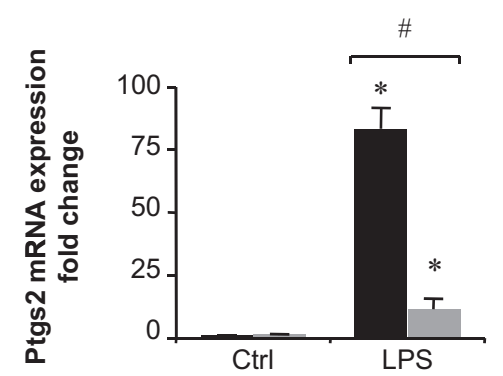

C

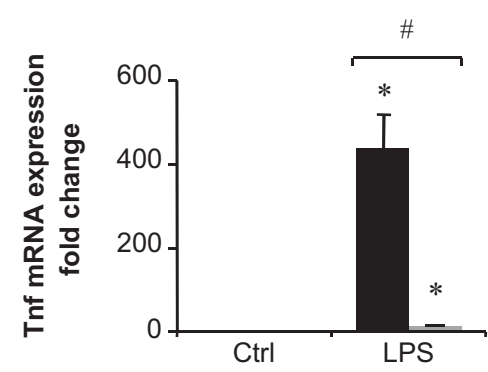

$\mathrm{D}$

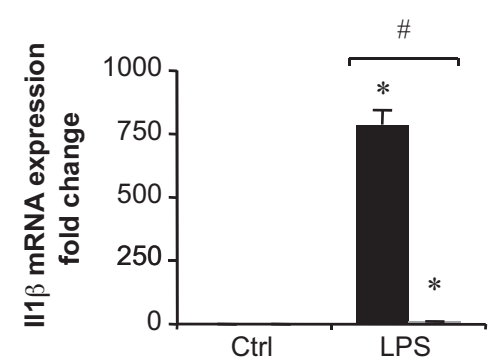

E

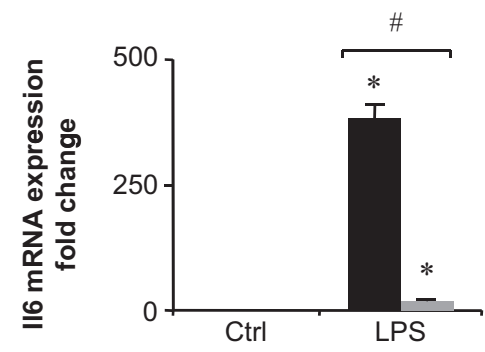

MGC1

AEC-M1

$\mathrm{F}$

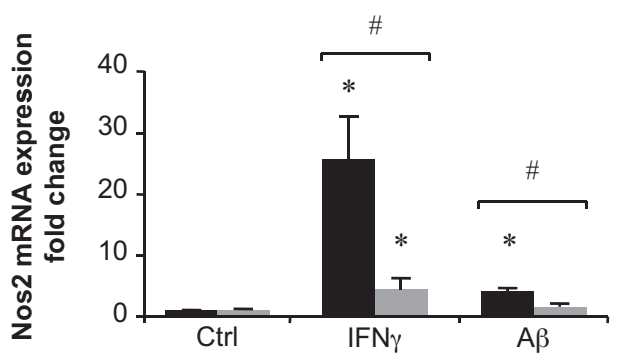

G

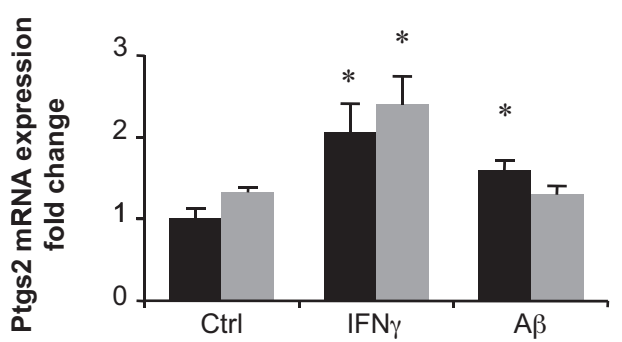

$\mathrm{H}$
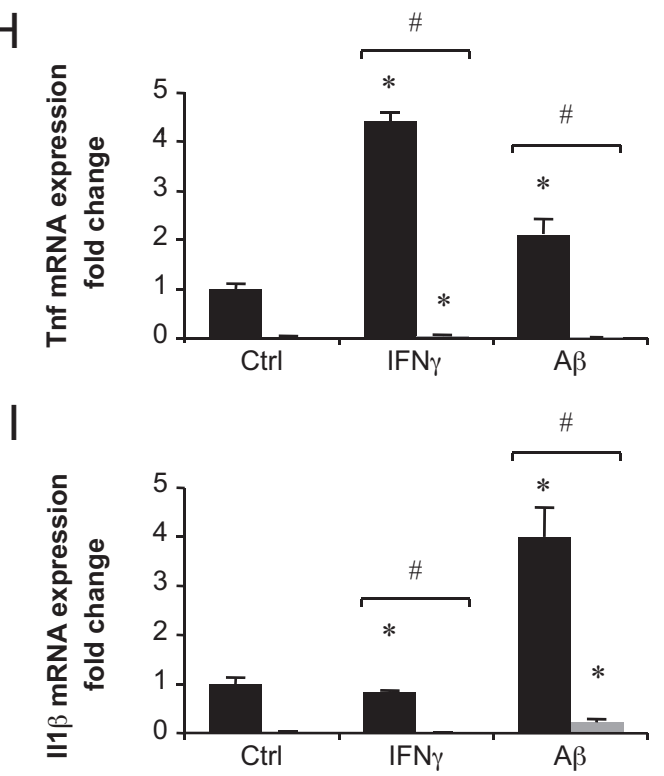

J

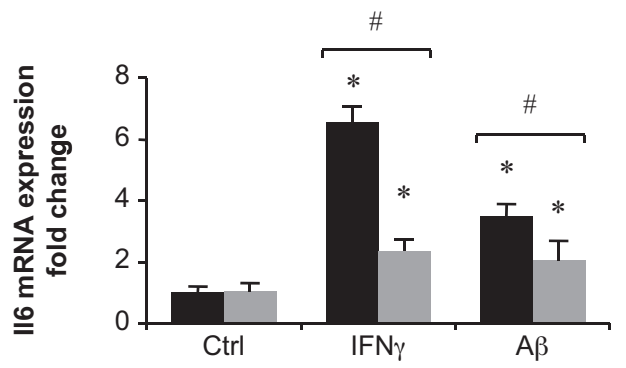

Fig. 4. Evaluation of pro-inflammatory gene expressions. Pro-inflammatory gene Nos2 (A and F), Ptgs2 (B and G), Tnf (C and H), Il1 $\beta$ (D and I) and Il6 (E and J) expressions were determined in MGC1 and AEC-M1 after $6 \mathrm{~h}$ of LPS $(1 \mu \mathrm{g} / \mathrm{ml})$, IFN $\gamma(50 \mathrm{U} / \mathrm{ml})$ and A $\beta(5 \mu \mathrm{M})$ exposure. The transcription levels were analyzed by real-time PCR. Control expression levels were fixed at 1.0 in mixed culture condition. All gene expressions were normalized to Rpl27 expression level. Results are given as mean \pm SEM ( $n=5$ independent experiments). ${ }^{*} p<0.05$, significantly different from control; ${ }^{*} p<0.05$, significantly different between MGC1 and AEC-M1.

a much stronger inflammatory response than any of the other cell populations. The three stimuli induced high expression levels of Nos2, Ptgs2, Tnf as well as the Ccl2 chemokine. However, an IFN $\gamma$ exposure reduced Il1 $\beta$ and $\mathrm{Ccl} 3$ expression in contrast to LPS and $\mathrm{A} \beta$ treatments.

\subsection{Effects of pro-inflammatory stimuli: assessment of inflammatory protein release}

As a result of Nos2, Ptgs2 and Tnf up-regulation, nitrites, $\mathrm{PGE}_{2}$ and TNF $\alpha$ releases increased significantly after treatments in MGC1 

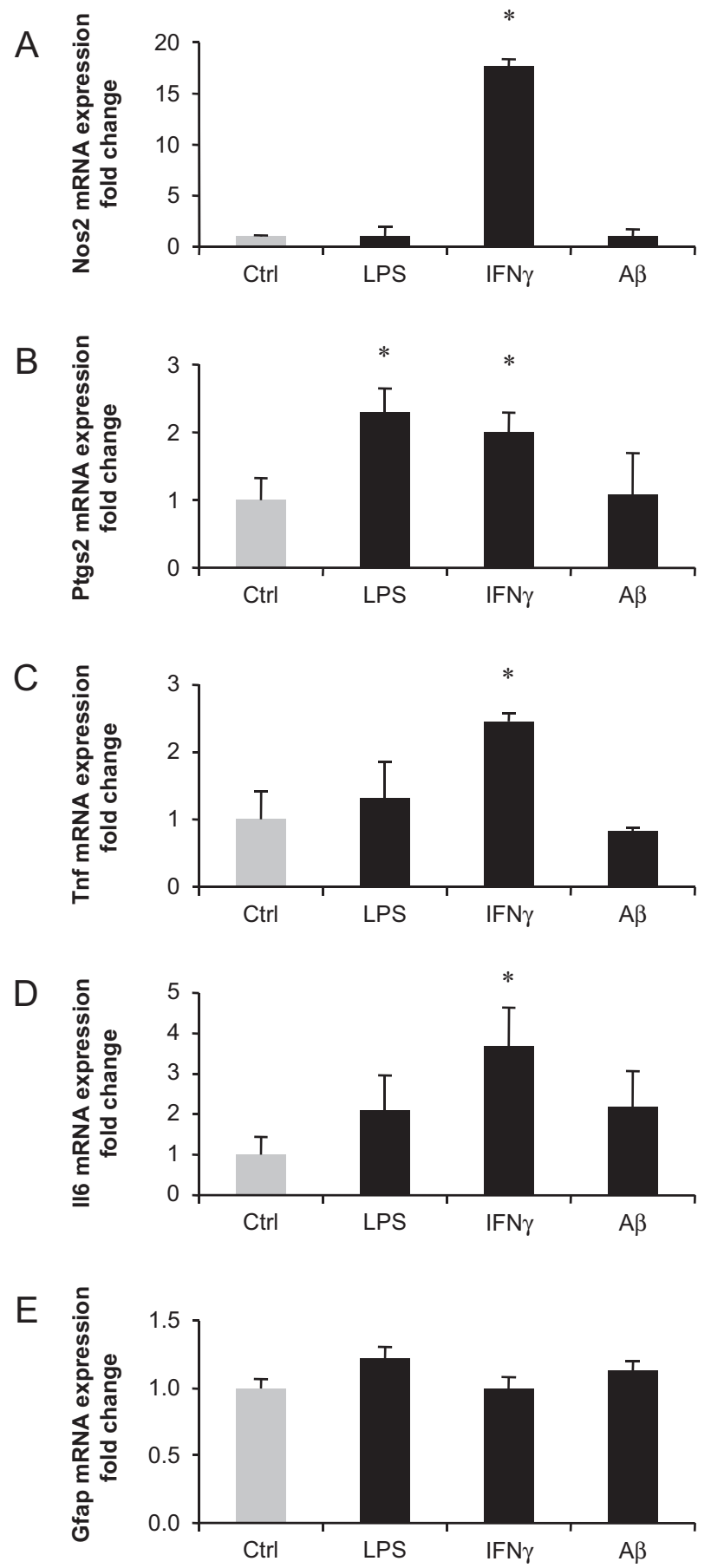

Fig. 5. Effect of pro-inflammatory compounds on neurosphere-derived astrocytes gene expression. Pro-inflammatory gene Nos2 (A), Ptgs2 (B), Tnf (C) and Il6 (D) expressions as well as Gfap expression (E) were determined in neurosphere-derived astrocytes after $6 \mathrm{~h}$ of LPS $(1 \mu \mathrm{g} / \mathrm{ml}), \mathrm{IFN} \gamma(50 \mathrm{U} / \mathrm{ml})$ and A $\beta(5 \mu \mathrm{M})$ exposure. The transcription levels were analyzed by real-time PCR. Control expression levels were fixed at 1.0. All gene expressions were normalized to Rpl27 expression level. Results are given as mean \pm SEM ( $n=3$ independent experiments). ${ }^{*} p<0.05$, significantly different from control.

(Fig. 6). The production of these pro-inflammatory compounds was higher under LPS conditions compared to IFN $\gamma$ or $A \beta$ exposures.

LPS, IFN $\gamma$ and $A \beta$ exposures induced an increase of nitrite levels in MGC1 at $24 \mathrm{~h}$ and $48 \mathrm{~h}$ (Fig. 6A). In AEC-M1, nitrite release levels were lower than in MGC1. A LPS treatment slightly increased the production of nitrites after $24 \mathrm{~h}$ (2-fold), but not after $48 \mathrm{~h}$. IFN $\gamma$ or $A \beta$ exposures did not promote nitrites production at both 24 and $48 \mathrm{~h}$ in AEC-M1.
An increase of $\mathrm{PGE}_{2}$ (Fig. 6B and C) and TNF $\alpha$ release (Fig. 6D and E) was observed in MGC1 after $24 \mathrm{~h}$ of LPS, IFN $\gamma$ and $A \beta$ exposure. In AEC-M1, the release of prostaglandins and TNF $\alpha$ induced by a LPS treatment was strongly lower (respectively $-95 \%$ and $-99 \%$ ) than in MGC1. An IFN $\gamma$ or $A \beta$ exposure was unable to promote $\mathrm{PGE}_{2}$ and TNF $\alpha$ releases in AEC-M1.

In addition, secreted amounts of nitrite, $\mathrm{PGE}_{2}$ and TNF $\alpha$ were similar when cells were treated for $24 \mathrm{~h}$ with IFN $\gamma$ or $A \beta$ in MGC1 or AEC-M1.

\subsection{Time dependent effects of a microglial contamination}

AEC-M1 were studied until 3 weeks after plating (Fig. 7). As shown in Fig. 7A, the number of microglial cells increased from 7 to 21 days of culture. As previously described, the GFAP staining was low at 7 days but higher after 21 days when microglial cells (Iba1 staining) were also numerous. A $6 \mathrm{~h}$ LPS exposure (Fig. 7B) increased Nos2, Ptgs2, Tnf and Il1 $\beta$ expression in a time dependent manner. Thereby, the pro-inflammatory state was higher after 21 days, which coincided with an elevated number of Iba1-positive cells.

\subsection{Comparison between single- and double-sorted glial cultures}

MGC1 were also compared to twice-sorted glial cultures, called AEC-M2 (Fig. 8). Itgam and Aif1 are genes coding respectively for the two proteins CD11b and Iba-1, exclusively expressed in microglia but not in astrocytes. AEC-M2 presented no Iba1-immunostaining (Fig. 8A) as well as no detectable microglial markers (Itgam and Aif1) mRNA expression (Fig. 8B). Compared to MGC1, AEC-M2 expressed lower GFAP expression levels (Fig. 8A and B). As a result of the absence of microglial cells, a pro-inflammatory LPS exposure had only minor effects on AEC-M2 and was subsequently not able to induce a real pro-inflammatory state (Fig. 8C).

\section{Discussion}

More than 35 years ago, Booher and Sensenbrenner developed in vitro methods for brain cells cultures (Booher and Sensenbrenner, 1972). For decades, these methods have been used by the research community. However, in the last few years, scientists have noticed that, due to their high reactivity potential, microglial cell contamination could alter the experimental response obtained from primary astrocytic cultures. For the purification of glial cells, several protocols are frequently found in the literature, like coating, subculturing or shaking methods. To reduce the presence of microglia or other contaminating cells, cytosine arabinoside, a specific toxin, anti-mitotic or lysosomotropic agents can also be employed (Saura, 2007; Hamby et al., 2006a). The mechanical shake-off method is the most widely used, which allows recovering microglial cells that are present above the astroglial monolayer. However, with this procedure, the exclusion of microglial cells from mixed glial cell cultures is incomplete. Indeed, this shaking method appears to be inefficient to remove microglial cells located below or inside the astroglial monolayer.

Here, we have compared mouse MGC1 (twice shaken and washed glial cultures), AEC-M1 (magnetic cell sorted cultures), AEC-M2 (twice-sorted cultures), neurosphere-derived astrocyte cultures and primary microglia cultures. From the mixed glial cultures, magnetic cell separation allows a single-step isolation of microglial cells (CD11b-positive fraction), but also AEC-M1 (CD11bnegative fraction). In this study, these different types of culture methods allowed us to evaluate the importance of the presence of microglial cells in the establishment and analysis of an inflammatory condition in glial cultures. 
A
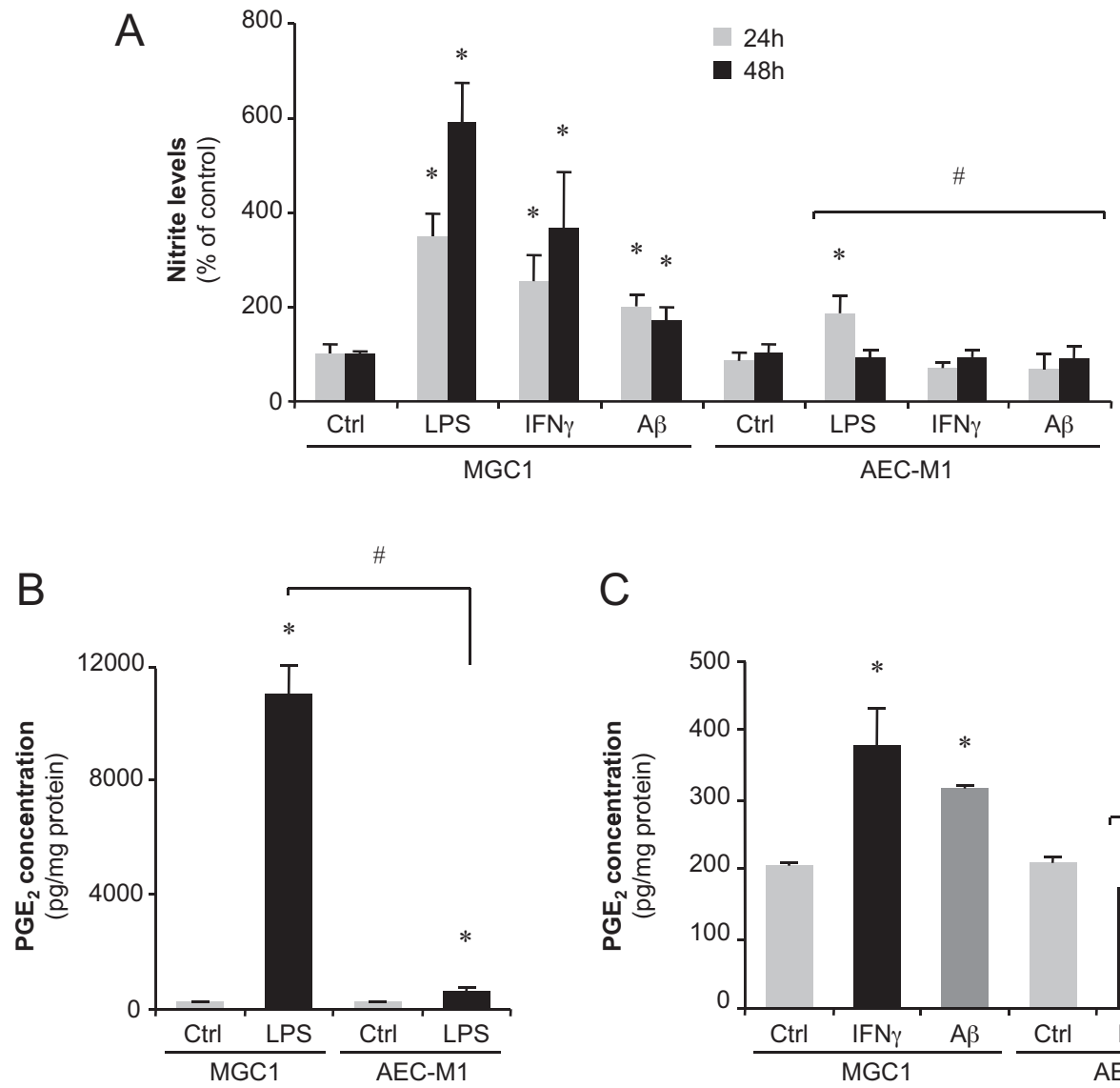

C
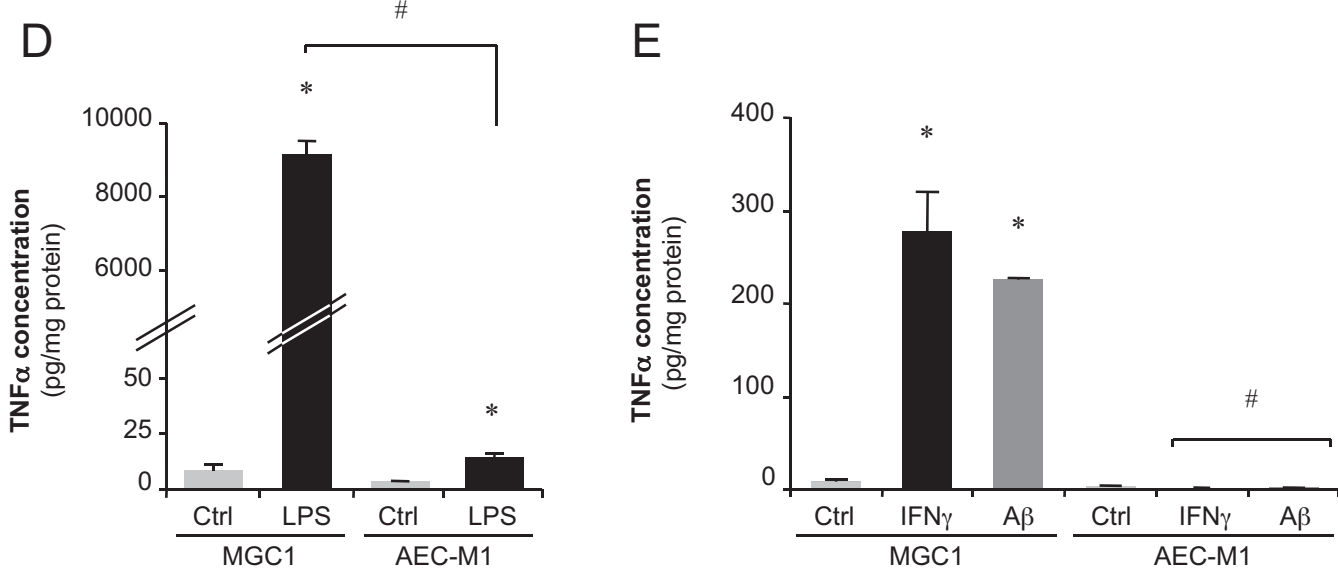

Fig. 6. Measurement of pro-inflammatory mediator releases. Nitrite (A), PGE 2 (B and C) and TNF $\alpha$ (D and E) releases were quantified after $24 \mathrm{~h}$ and $48 \mathrm{~h}$ (for nitrites only) of LPS $(1 \mu \mathrm{g} / \mathrm{ml})$, IFN $\gamma(50 \mathrm{U} / \mathrm{ml})$ or $\mathrm{A} \beta(5 \mu \mathrm{M})$ exposure in supernatant of MGC1 and AEC-M1. Results are given as mean \pm SEM $\left(n=3\right.$ independent experiments). ${ }^{*} p<0.05$, significantly different from control; ${ }^{*} p<0.05$, significantly different between MGC1 and AEC-M1.

The first part of this work aimed at determining the proportion of microglia in MGC1 and AEC-M1. By immunocytochemistry, we confirmed that Iba1-positive cells are present in mouse MGC1 even after two shaking and washing steps. Conversely, after CD11b magnetic separation, the proportion of Iba1-positive cells in the negative fraction, corresponding to the AEC-M1, was, as expected, much lower than in mixed cultures. The immunostaining of the glial fibrillary acidic protein (GFAP), an intermediate filament component of astroglial cells (Bramanti et al., 2010; Röhl et al., 2007), was slightly higher in MGC1 than in AEC-M1. GFAP is a tightly regulated protein, whose expression is induced by multiple factors such as brain injury and diseases (Middeldorp and Hol, 2011).
Removing microglial cells from culture promoted a decrease of the basal levels of secreted compounds like TNF $\alpha$. Thus, a decrease of the astrocytic reactivity related to a down-regulation of GFAP expression was subsequently observed. The amount of microglial cells in glial cultures was accurately determined by flow cytometry experiments. A CD11b magnetic separation decreased the Iba1-positive cells from 9 to $10 \%$ in MGC1 to 1-1.5\% in AEC-M1.Consequently, the GFAP-positive cells increased from 60\% in MGC1 to $70 \%$ in AEC-M1. These results are in accordance with recent assessments of glial populations in cultures (Marek et al., 2008). Besides, cells that were negative for microglial and astroglial markers in both cultures were probably mainly precursors and differentiated 

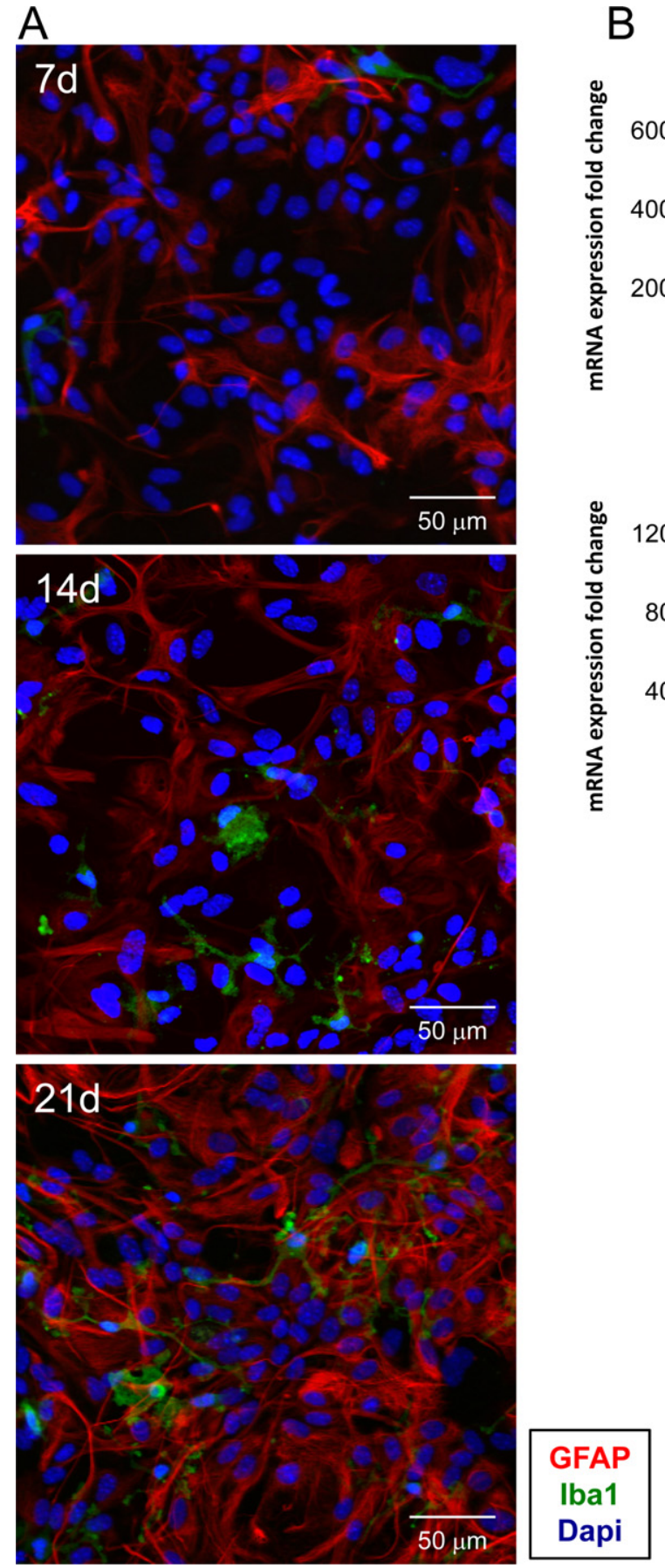

B

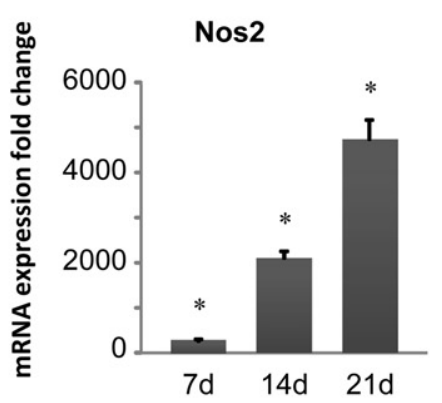

Tnf

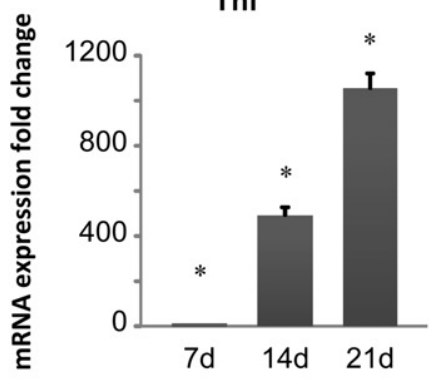

Ptgs2

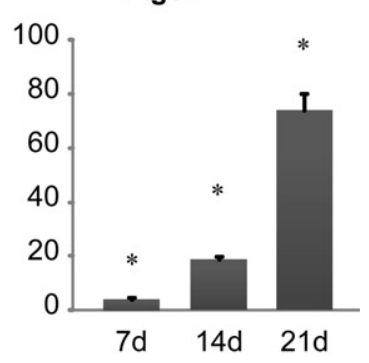

$\| 1 \beta$

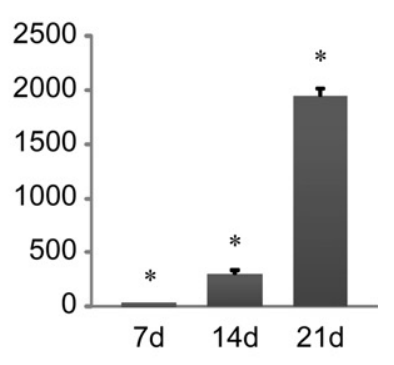

Fig. 7. Time-dependent effect of a microglial contamination. AEC-M1 were cultured for 7, 14 and 21 days after CD11b-magnetic cell sorting. These cells were labeled with anti-GFAP antibody (red) in combination with the microglial marker Iba1 (green) and counterstained with nuclear stain DAPI (blue) at the different time points (A). Pro-inflammatory gene Nos2, Ptgs2, Tnf and Il1 $\beta$ expressions (B) were also determined in these cultures after $6 \mathrm{~h}$ of LPS (1 $\mu \mathrm{g} / \mathrm{ml})$ exposure. The transcription levels were analyzed by real-time PCR. Control expression levels were fixed at 1.0. All gene expressions were normalized to Rpl27 expression level. Results are given as mean \pm SEM ( $n=3$ independent experiments). ${ }^{*} p<0.05$, significantly different from control. (For interpretation of the references to color in this figure legend, the reader is referred to the web version of this article.)

oligodendrocytes, but also GFAP-negative astrocytes. In fact, it has been reported that some astrocytes populations in healthy CNS do not express, or express at low level, GFAP (Sofroniew and Vinters, 2010; Sofroniew, 2009; Buffo et al., 2008).

Microglia, the most reactive cells against pro-inflammatory stimuli, detect and respond rapidly to pro-inflammatory triggers (Lull and Block, 2010; Kim and Joh, 2006). Based on previous papers, astrocyte-mediated effects are completely masked when cultures contain a large population of microglia. For this reason, we agree with the authors who have underlined the necessity to minimize the proportion of microglial cells in glial cultures (Marek et al., 2008; Saura, 2007; Hamby et al., 2006a,b; Hewett et al., 1999). Thus, in this work, we have made a direct comparison between cultures with a known percentage of microglia contamination and cultures with minimal or no microglia. To induce an inflammatory environment, we treated our glial cultures with proinflammatory compounds, known to promote cellular activation by distinct biological pathways. Thus, we have used a nuclear 
A

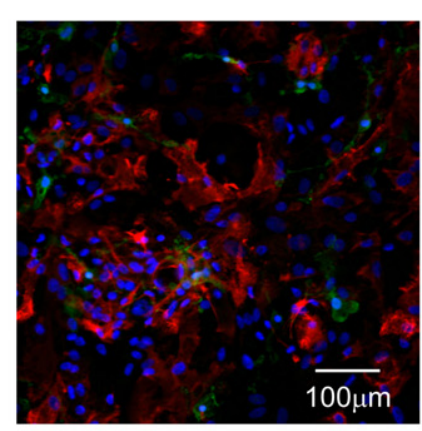

AEC-M2

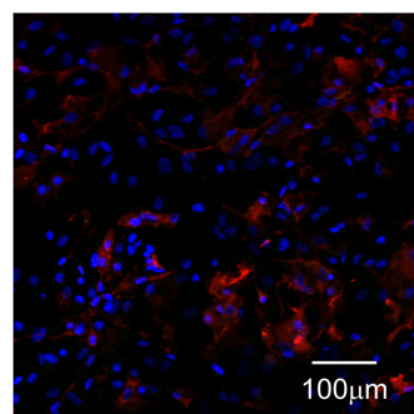

\section{GFAP \\ Iba1 \\ Dapi}

B

\begin{tabular}{|c|c|c|}
\hline & MGC1 & AEC-M2 \\
\hline Gfap & $\begin{array}{c}1.00 \pm 0.09 \\
\left(C_{\mathrm{t}}=20.2\right)\end{array}$ & $\begin{array}{c}0.67 \pm 0.12 \\
\left(\mathrm{C}_{\mathrm{t}}=20.8\right)\end{array}$ \\
\hline Itgam & $\begin{array}{c}1.00 \pm 0.10 \\
\left(\mathrm{C}_{\mathrm{t}}=28.2\right)\end{array}$ & Not detectable \\
\hline Aif1 & $\begin{array}{c}1.00 \pm 0.06 \\
\left(\mathrm{C}_{\mathrm{t}}=24.4\right)\end{array}$ & Not detectable \\
\hline
\end{tabular}

C

MGC1

AEC-M2
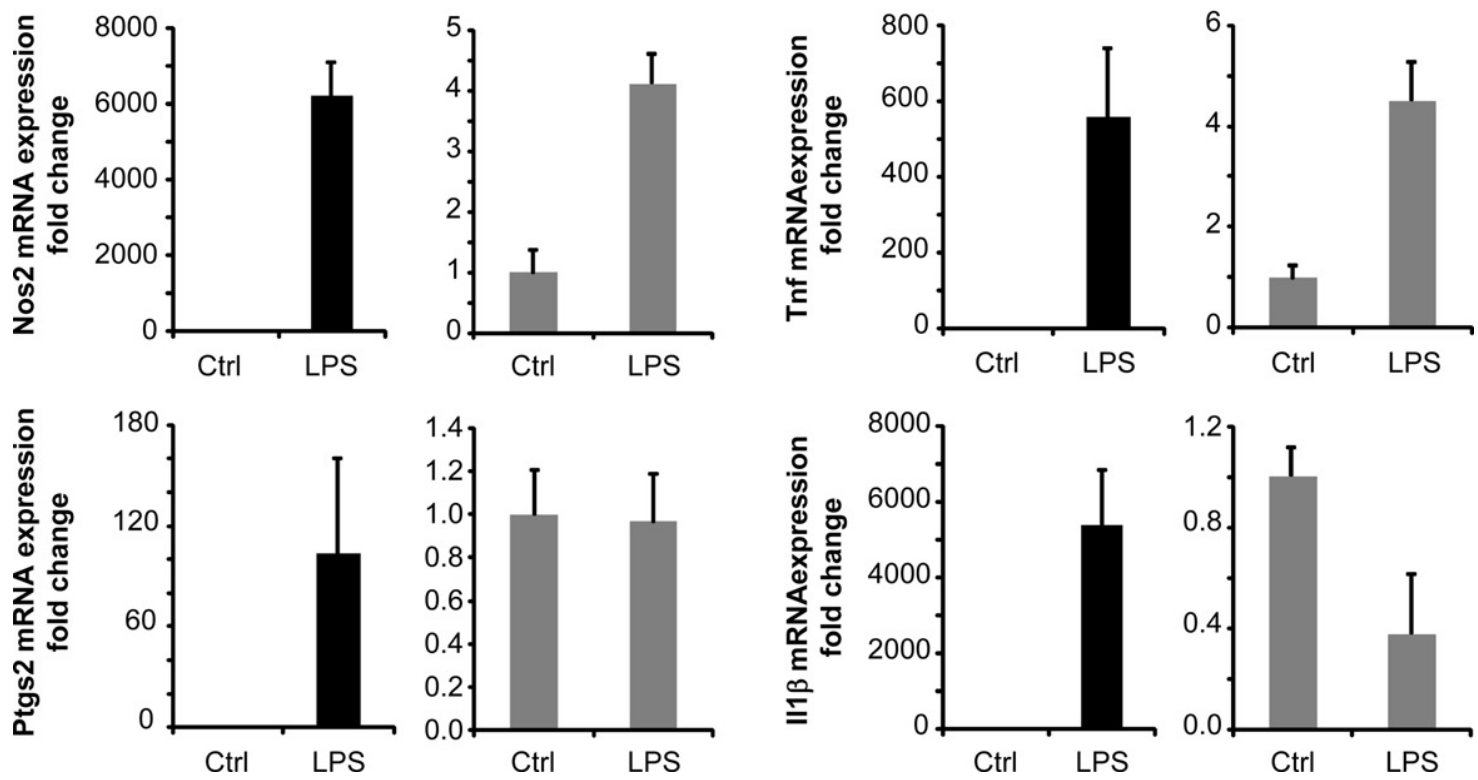

Fig. 8. Comparison of MGC1 with AEC-M2. Both glial cells cultures were labeled with anti-GFAP antibody (red) in combination with the microglial marker Iba1 (green) and counterstained with nuclear stain DAPI (blue) (A). Transcription levels and $C_{\mathrm{t}}$ values of the astrocytic marker (Gfap) as well as microglial markers (Itgam and Aif1) were evaluated by real-time PCR in control condition in both glial cultures (B). Cultures were also treated with LPS ( $1 \mu \mathrm{g} / \mathrm{ml})$ for $6 \mathrm{~h}$. The transcription levels of the pro-inflammatory genes Nos2, Ptgs2, Tnf and Il1 $\beta$ were analyzed by real-time PCR (C). Control expression levels were fixed at 1.0. All gene expressions were normalized to Rpl27 expression level. Results are given as mean $\pm \operatorname{SEM}$ ( $n=3$ independent experiments). (For interpretation of the references to color in this figure legend, the reader is referred to the web version of this article.)

factor kappa B (NFKB) pathway-inducer (LPS) (Carmody and Chen, 2007), a janus kinase-signal transducer and activator of transcription (JAK-STAT) pathway-inducer (IFN $\gamma$ ) (Gough et al., 2008) as well as the beta-amyloid peptide (1-42) $(\mathrm{A} \beta)$ in an oligomeric conformation (Heurtaux et al., 2010). In recent studies, we have demonstrated that LPS, IFN $\gamma$, as well as the oligomeric form of the $A \beta$ peptide were able to strongly activate microglial cells (Heurtaux et al., 2010; Michelucci et al., 2009). At the transcriptional level, we have observed that $6 \mathrm{~h}$ of LPS exposure in MGC1 induced a higher pro-inflammatory state than an IFN $\gamma$ or $A \beta$ exposure. This pro-inflammatory status appeared to be lower in AEC-M1 where microglial cells were almost absent. In these AEC-M1, a $6 \mathrm{~h} \mathrm{~A} \beta$ exposure was unable to up-regulate Nos2, Ptgs2 and Tnf mRNA expression and only slightly induced Il $1 \beta$ and Il6 expression. Thus, a short single $A \beta$ treatment had poor effects on AEC-M1 activation. In addition, as a result of gene expression modulation, we 
have also observed that pro-inflammatory mediators (nitrites, $\mathrm{PGE}_{2}$ and TNF $\alpha$ ) releases were strongly decreased in AEC-M1 compared to MGC1 both treated with either LPS, IFN $\gamma$ or $A \beta$. Interestingly, results obtained with $A \beta$ clearly showed that a short treatment was unable to activate AEC-M1. This is in accordance with a recent study (Ebenezer et al., 2010). In this work, we have used an oligomeric $A \beta$ preparation, which is known to strongly activate microglial cells. These results support the hypothesis that activation of astrocytes around $A \beta$ deposits in Alzheimer's disease may be due to prior microglial activation inducing finally a chronic inflammatory state. It is well documented that activated microglia represent a major source of inflammatory factors. In this study, we have described that primary microglia strongly reacted to LPS exposure (Table 3 ). The presence of IFN $\gamma$ or $A \beta$ peptide also induced a pro-inflammatory phenotype in primary microglial cells. Microglia appeared to be more sensitive to LPS, IFN $\gamma$ and $\mathrm{A} \beta$ treatments than AEC-M1 and MGC1. The strong up-regulation of the pro-inflammatory genes underlined the importance of a microglial contamination even if the percentage of these cells is lower than $10 \%$ of the total cells in culture. Thus, to confirm the importance of microglia in the initiation of an inflammatory environment, we have also realized a control by using cultures devoid of microglial cells. These microglia-free astrocyte cultures were obtained after differentiation of neurospheres (Crocker et al., 2008). Challenging these cultures with either LPS, IFN $\gamma$ or $A \beta$ had only little effect on the up-regulation of pro-inflammatory genes. With the exception of LPS treatment, which is a strong microglial activator, the inflammatory response in AEC-M1 and neurosphere-derived pure astrocyte cultures are obviously very closed. Thus, both cultures represent similar in vitro models for astrocyte studies. These results are in accordance with published work (Crocker et al., 2008). In the same way, Hamby et al. (2006a) reported a method for eradicating microglia from primary glial cultures. The authors treated confluent astrocyte monolayers with a mitotic inhibitor (cytosine $\beta$-D-arabinofuranoside) followed by a brief exposure to high concentrations of a lysosomotrophic agent (L-leucine methyl ester, LME). By this method, they generated highly purified astrocytes without the need for cell passage. Their results are quite similar to our results and confirm the necessity to eliminate microglia from glial cultures. However, this method using the LME lysosomotrophic agent only permits to obtain near-pure astrocyte cultures when our magnetic separation permits to obtain rapidly both near-pure astrocyte cultures and pure microglial cultures.

Bacterial endotoxin receptors, mainly Toll-like receptor 4 (TLR4), are implicated in LPS bioactivity (Peri et al., 2010). However, in these neurosphere-derived astrocytes, the LPS-TLR4 signaling pathway does not seem to be operational. This observation could be linked to the low level of TLR4 expression in astrocytes (Mishra et al., 2006; Jack et al., 2005). TLR4 receptor is documented to be present on circulating monocytes, macrophages and other systemic immune cells. We have also demonstrated that microglia strongly express TLR4 whereas astrocytes do not express it (data not shown). These data are in accordance with a previous work (Lehnardt et al., 2002). Moreover, due to the high TLR4 expression level in microglia (Buchanan et al., 2010; Mishra et al., 2006; Jack et al., 2005), treating glial cultures with LPS could represent a way to confirm their presence. Furthermore, the basal expression levels of pro-inflammatory genes (Tnf, Il1 $\beta$ and $\mathrm{Ccl} 3$ ), as well as those of specific microglial markers (Itgam and Aif1) are higher in primary microglia than in MGC1 (Table 2). In AEC-M1 and in neurospherederived astrocytes, the expression levels are even lower (threshold cycle $C_{\mathrm{t}}>30$ ). According to these data, the level of microglial cell contamination could also be evaluated by a simple comparison of the threshold cycle of these pro-inflammatory genes or microglial markers in basal conditions in cultures.
We have also described time-dependent effects of a microglial contamination. AEC-M1 were studied up until 3 weeks after plating. The percentage of Iba1-positive cells increased in a time dependent manner in these non-treated confluent glial cultures. Possibly as a result of the increased number of microglia, the GFAP expression level was also enhanced. This is in accordance with our observations, where we described that astrocytic reactivity and GFAP expression were increased in the presence of microglial cells (Fig. 2). Moreover, a LPS exposure induced a time dependent proinflammatory state, which was higher after 3 weeks of culture, and coincided with the presence of a high number of contaminating microglial cells. Finally, we have compared MGC1 and AEC-M2 (twice-sorted glial cultures). The AEC-M2 presented a lower GFAP expression level and no detectable microglial markers expression. Furthermore, a LPS exposure was not able to induce a real proinflammatory state, thus confirming the absence of microglial cells with this culturing procedure.

In our conditions, we clearly show that microglia-depleted cultures (AEC-M1/M2 and neurosphere-derived astrocytes) are weakly activated by pro-inflammatory agents. The presence of microglia appears to be crucial in the establishment of an inflammatory state. There is growing interest about the role of glial cells in neurodegenerative pathologies (Amor et al., 2010; Hamby and Sofroniew, 2010; Perry et al., 2010). On one hand, the isolation of glial cells allows studying the responsiveness of each cell type to pro-inflammatory agents. On the other hand, the use of mixed cultures could reflect the physiological condition and could be useful to observe global modifications and cellular interactions characterizing CNS disorders. Microglial cells rapidly and strongly react to brain insults. Due to their high reactivity to various aggressions or pro-inflammatory stimuli, microglia-derived effects might be credited to astrocytes in mixed cultures. In these conditions, the subsequent reactive astrocytes interact in a complex manner with microglia and can exert pro-inflammatory but also anti-inflammatory effects (Fuller et al., 2010; Zhang et al., 2010).

In conclusion, our results suggest the necessity to rigorously check the purity of glial cultures. Attention should be paid to the presence of microglia in glial cultures because of their potential alteration of the results, especially when inflammatory processes are investigated. For that reason, the magnetic cell sorting technology appears to be an efficient and rapid method to limit microglial contamination in glial cultures. In addition, it allows to rapidly obtain near-pure astrocyte cultures but also pure microglial cultures.

\section{Conflict of interest statement}

No conflicts of interest exist.

\section{Acknowledgements}

This work was financed through grants from the National Research Fund of Luxembourg and the University of Luxembourg. We thank Drs. A. Michelucci and M. Buttini for editing the manuscript.

\section{References}

Amor S, Puentes F, Baker D, van der Valk P. Inflammation in neurodegenerative diseases. Immunology 2010;129:154-69.

Beutner C, Roy K, Linnartz B, Napoli I, Neumann H. Generation of microglial cells from mouse embryonic stem cells. Nat Protoc 2010;5:1481-94.

Block ML, Zecca L, Hong JS. Microglia-mediated neurotoxicity: uncovering the molecular mechanisms. Nat Rev Neurosci 2007:8:57-69 [Review].

Booher J, Sensenbrenner M. Growth and cultivation of dissociated neurons and glial cells from embryonic chick, rat and human brain in flask cultures. Neurobiology 1972;2:97-105. 
Bramanti V, Tomassoni D, Avitabile M, Amenta F, Avola R. Biomarkers of glial cell proliferation and differentiation in culture. Front Biosci (Schol Ed) 2010;2:558-70 [Review].

Buchanan MM, Hutchinson M, Watkins LR, Yin H. Toll-like receptor 4 in CNS pathologies. J Neurochem 2010;114:13-27 [Review].

Buffo A, Rite I, Tripathi P, Lepier A, Colak D, Horn AP, et al. Origin and progeny of reactive gliosis: a source of multipotent cells in the injured brain. Proc Natl Acad Sci U S A 2008; 105:3581-6.

Carmody RJ, Chen YH. Nuclear factor-kappaB: activation and regulation during tolllike receptor signaling. Cell Mol Immunol 2007;4:31-41.

Cho SH, Chen CH, Tsai FS, Godin JM, Lo YH. Human mammalian cell sorting using a highly integrated micro-fabricated fluorescence-activated cell sorter (microFACS). Lab Chip 2010;10:1567-73.

Crocker SJ, Frausto RF, Whitton JL, Milner R. A novel method to establish microglia-free astrocyte cultures: comparison of matrix metalloproteinase expression profiles in pure cultures of astrocytes and microglia. Glia 2008;56: 1187-98.

Dainiak MB, Kumar A, Galaev IY, Mattiasson B. Methods in cell separations. Adv Biochem Eng Biotechnol 2007;106:1-18.

Dobrenis K. Microglia in cell culture and in transplantation therapy for central nervous system disease. Methods 1998;16:320-44 [Review].

Ebenezer PJ, Weidner AM, Levine Iii H, Markesbery WR, Murphy MP, Zhang L, et al. Neuron specific toxicity of oligomeric amyloid- $\beta$ : role for JUN-kinase and oxidative stress. J Alzheimers Dis 2010;22:839-48.

Ekdahl CT, Kokaia Z, Lindvall O. Brain inflammation and adult neurogenesis: the dual role of microglia. Neuroscience 2009;158:1021-9 [Review].

Farfara D, Lifshitz V, Frenkel D. Neuroprotective and neurotoxic properties of glial cells in the pathogenesis of Alzheimer's disease. J Cell Mol Med 2008:12:762-80.

Floden AM, Combs CK. Microglia repetitively isolated from in vitro mixed glial cultures retain their initial phenotype. J Neurosci Methods 2007;164:218-24.

Fuller S, Steele M, Münch G. Activated astroglia during chronic inflammation in Alzheimer's disease - do they neglect their neurosupportive roles. Mutat Res 2010;690:40-9.

Fuss IJ, Kanof ME, Smith PD, Zola H. Isolation of whole mononuclear cells from peripheral blood and spinal cord. Curr Protocol Immunol 2009 [chapter 7: unit 7.1].

Gough DJ, Levy DE, Johnstone RW, Clarke CJ. IFNgamma signaling-does it mean JAKSTAT. Cytokine Growth Factor Rev 2008;19:383-94.

Graham JM. Isolation of lysosomes from tissues and cells by differential and density gradient centrifugation. Curr Protoc Cell Biol 2001 [chapter 3: unit 3.6].

Grandbarbe L, Bouissac J, Rand M, Hrabé de Angelis M, Artavanis-Tsakonas $S$, Mohier E. Delta-notch signaling controls the generation of neurons/glia from neural stem cells in a stepwise process. Development 2003;130: 1391-402.

Hamby ME, Sofroniew MV. Reactive astrocytes as therapeutic targets for CNS disorders. Neurotherapeutics 2010;7:494-506.

Hamby ME, Uliasz TF, Hewett SJ, Hewett JA. Characterization of an improved procedure for the removal of microglia from confluent monolayers of primary astrocytes. J Neurosci Methods 2006a;150:128-37.

Hamby ME, Hewett JA, Hewett SJ. TGF-beta1 potentiates astrocytic nitric oxide production by expanding the population of astrocytes that express NOS-2. Glia 2006b;54:566-77.

Hanisch UK, Kettenmann H. Microglia: active sensor and versatile effector cells in the normal and pathologic brain. Nat Neurosci 2007;10:1387-94.

Henze C, Hartmann A, Lescot T, Hirsch EC, Michel PP. Proliferation of microglial cells induced by 1-methyl-4-phenylpyridinium in mesencephalic cultures results from an astrocyte-dependent mechanism: role of granulocyte macrophage colony-stimulating factor. J Neurochem 2005;95:1069-77.

Heurtaux T, Michelucci A, Losciuto S, Gallotti C, Felten P, Dorban G, et al. Microglial activation depends on beta-amyloid conformation: role of the formylpeptide receptor 2. J Neurochem 2010;114:576-86.
Hewett JA, Hewett SJ, Winkler S, Pfeiffer SE. Inducible nitric oxide synthase expression in cultures enriched for mature oligodendrocytes is due to microglia. J Neurosci Res 1999;56:189-98.

Jack CS, Arbour N, Manusow J, Montgrain V, Blain M, McCrea E, et al. TLR signaling tailors innate immune responses in human microglia and astrocytes. J Immunol 2005; 175:4320-30.

Jana M, Jana A, Pal U, Pahan K. A simplified method for isolating highly purified neurons, oligodendrocytes, astrocytes, and microglia from the same human fetal brain tissue. Neurochem Res 2007;32:2015-22.

Kim YS, Joh TH. Microglia, major player in the brain inflammation: their roles in the pathogenesis of Parkinson's disease. Exp Mol Med 2006;38:333-47 [Review].

Lara OR, Chalmers JJ. Cell enrichment and immunochemical staining. Methods Mol Biol 2005;295:301-10.

Lehnardt S, Lachance $C$, Patrizi S, Lefebvre S, Follett PL, Jensen FE, et al. The tolllike receptor TLR4 is necessary for lipopolysaccharide-induced oligodendrocyte injury in the CNS. J Neurosci 2002;22:2478-86.

Liu W, Tang Y, Feng J. Cross talk between activation of microglia and astrocytes in pathological conditions in the central nervous system. Life Sci 2011;89:141-6 [Review].

Lull ME, Block ML. Microglial activation and chronic neurodegeneration. Neurotherapeutics 2010;7:354-65.

Marek R, Caruso M, Rostami A, Grinspan JB. Das Sarma J. Magnetic cell sorting: a fast and effective method of concurrent isolation of high purity viable astrocytes and microglia from neonatal mouse brain tissue. J Neurosci Methods 2008;175:108-18.

Michelucci A, Heurtaux T, Grandbarbe L, Morga E, Heuschling P. Characterization of the microglial phenotype under specific pro-inflammatory and anti-inflammatory conditions: effects of oligomeric and fibrillar amyloid-beta. J Neuroimmunol 2009;210:3-12.

Middeldorp J, Hol EM. GFAP in health and disease. Prog Neurobiol 2011;93: 421-43.

Mishra BB, Mishra PK, Teale JM. Expression and distribution of Toll-like receptors in the brain during murine neurocysticercosis. J Neuroimmunol 2006:181:46-56.

Peri F, Piazza M, Calabrese V, Damore G, Cighetti R. Exploring the LPS/TLR4 signal pathway with small molecules. Biochem Soc Trans 2010;38:1390-5.

Perry VH, Nicoll JA, Holmes C. Microglia in neurodegenerative disease. Nat Rev Neurol 2010;6:193-201.

Röhl C, Lucius R, Sievers J. The effect of activated microglia on astrogliosis parameters in astrocyte cultures. Brain Res 2007;1129:43-52

Saijo K, Winner B, Carson CT, Collier JG, Boyer L, Rosenfeld MG, et al. A Nurr1/CoREST pathway in microglia and astrocytes protects dopaminergic neurons from inflammation-induced death. Cell 2009;137:47-59.

Saura J. Microglial cells in astroglial cultures: a cautionary note. J Neuroinflamm 2007;4:26 [Review].

Sofroniew MV. Molecular dissection of reactive astrogliosis and glial scar formation. Trends Neurosci 2009;32:638-47 [Review].

Sofroniew MV, Vinters HV. Astrocytes: biology and pathology. Acta Neuropathol 2010;119:7-35.

Solenov E, Watanabe H, Manley GT, Verkman AS. Sevenfold-reduced osmotic water permeability in primary astrocyte cultures from AQP-4-deficient mice, measured by a fluorescence quenching method. Am J Physiol Cell Physiol 2004:286:426-32.

Vallejo R, Tilley DM, Vogel L, Benyamin R. The role of glia and the immune system in the development and maintenance of neuropathic pain. Pain Pract 2010;10:167-84 [Review].

Zaheer A, Mathur SN, Lim R. Overexpression of glia maturation factor in astrocytes leads to immune activation of microglia through secretion of granulocyte-macrophage-colony stimulating factor. Biochem Biophys Res Commun 2002;294:238-44

Zhang D, Hu X, Qian L, O'Callaghan JP, Hong JS. Astrogliosis in CNS pathologies: is there a role for microglia? Mol Neurobiol 2010;41:232-41 [Review]. 